\title{
Os fundamentos essenciais da argumentação no ensino de Ciências: um estudo a partir das unidades, elementos taxonômicos e qualidade do argumento $^{+*}$
}

Geraldo Fernandes ${ }^{1}$

Universidade Federal dos Vales do Jequitinhonha e Mucuri

Diamantina - MG

António M. Rodrigues ${ }^{1}$

Carlos A. Ferreira ${ }^{l}$

Faculdade de Motricidade Humana - Universidade de Lisboa

Unidade de Investigação e Desenvolvimento em Educação e Formação

Instituto de Educação

Lisboa - Portugal

\section{Resumo}

Este estudo tem por objetivo compreender as discussões argumentativas estabelecidas por crianças durante o desenvolvimento de Atividades de Investigação no Ensino de Ciências (AIEC). Para isso, elaboramos dois instrumentos de análise da argumentação. O primeiro, denominado de Elementos Taxonômicos da Argumentação Científica (ETAC), procura caracterizar a estrutura e a progressão do argumento e o segundo, denominado de Qualidade do Argumento Modificado, visa hierarquizar o argumento em diferentes níveis. Para exemplificar o uso desses instrumentos, foi analisado o argumento de crianças e jovens em uma oficina que trabalhou com conceitos de Física sobre o "Voo dos Aviões”. Como resultado, as categorias evidenciadas pelos ETAC não podem ser pensadas como unidades isoladas e autônomas, mas sim num continuum de evolução, caracterizando-se em movimentos discursivos do mais simples ao mais complexo.

\footnotetext{
+ The essential foundations of argumentation in science education: a study from the units, taxonomic elements and quality of the argument

* Recebido: maio de 2018. Aceito: outubro de 2018.

${ }^{1}$ E-mails: gerawell@gmail.com; arodrigues@fmh.ulisboa.pt; cferreira@fmh.ulisboa.pt
} 
Palavras-chave: Argumentação científica; Ensino de Ciências por Investigação; Elementos Taxonômicos da Argumentação Científica.

\begin{abstract}
This study aims to understand the argumentative discussions established by children during the development of Inquiry-based Activities in Science Education (IBASE). For this, we elaborated two instruments of analysis of the argumentation. The first, called Taxonomical Elements of Scientific Argumentation (TESA), seeks to characterize the structure and progression of the argument and the second, called Quality of the Modified Argument, aims to rank the argument at different levels. To exemplify the use of these instruments, the children's and young people's argument was analyzed in a scientific workshop on "Flight of the Airplanes". As a result, the categories evidenced by TESAs cannot be thought of as isolated and autonomous units, but rather as a continuum of evolution, characterizing in discursive movements from the simplest to the most complex.
\end{abstract}

Keywords: Scientific argumentation; Inquiry Activities in Science Education; Taxonomic Elements of Scientific Argumentation.

\title{
I. Introdução
}

Nos últimos anos, assistiu-se a um crescente número de estudos sobre a argumentação de crianças e jovens (oral, escrita e gestual) em contexto de aprendizagem de ciências (DRIVER; NEWTON, 1997; SASSERON, 2008). Um grupo de estudos destaca a importância da argumentação na construção do conhecimento científico através do desenvolvimento de atividades investigativas no contexto escolar (CHIN; OSBORNE, 2010; ERDURAN; SIMON; OSBORNE, 2004; GARCIA-MILA; GILABERT; ERDURAN; FELTON, 2013; JIMÉNEZ-ALEIXANDRE; PUIG, 2012; OSBORNE; ERDURAN; SIMON, 2004). Outro grupo de estudos destaca a perspectiva sociocultural (MORTIMER; SCOTT, 2003; SCOTT; MORTIMER, 2005; VYGOTSKY, 1980, 1986), que aponta para o papel da interação social nos processos de aprendizagem e de pensamento (MORTIMER; SCOTT, 2003; SCOTT; MORTIMER, 2005).

Este estudo tem por objetivo analisar o argumento de um grupo de crianças e jovens em um cenário de ensino não formal e apoiado por diferentes recursos de aprendizagem visando o desenvolvimento de atividades investigativas no ensino de ciências (AIEC). Neste sentido, buscamos responder a seguinte questão: Como se caracteriza o argumento de crianças e jovens em um contexto não formal de ensino de Ciências? 
Para responder a nossa questão de investigação, elaboramos dois instrumentos: os Elementos Taxonômicos da Argumentação Científica (ETAC) e a Qualidade do Argumento Modificado (QAM). Assim, o estudo do processo da argumentação em sala de aula e em outros contextos, bem como da sua estrutura e qualidade, passa a ser o principal objetivo desta discussão, fundamentalmente no que diz respeito à compreensão do desenvolvimento de atividades de ensino de Ciências.

Para compreendermos melhor a nossa proposta, organizamos a fundamentação teórica deste trabalho em quatro fundamentos ou características da argumentação científica: (1) a estrutura ou a complexidade do argumento; (2) a qualidade de um argumento; (3) o processo de movimento e progressão do argumento; e (4) a construção social do argumento.

\section{Argumentação no ensino de ciências: definições e fundamentos essenciais}

\section{II.1 Definindo argumento e argumentação}

A necessidade de compreender a alfabetização científica conduziu a um aumento significativo no número de estudos baseados em argumentos e argumentação (CAVAGNETTO, 2010; SASSERON; CARVALHO, 2009). Muitos destes estudos sugerem que o uso de argumentos científicos pelos alunos é passível de desenvolver capacidades comunicacionais, consciência metacognitiva, pensamento crítico, compreensão da cultura e da prática da ciência e alfabetização científica (CAVAGNETTO, 2010).

Berland (2011) vê a argumentação científica como "uma prática dialógica na qual os indivíduos comparam diferentes ideias de forma a fazer sentido a questão em estudo" (p. 630, tradução nossa). Por outro lado, Berland e Hammer (2012) descrevem a argumentação científica "como uma forma de expor e confrontar incoerências entre as ideias e as evidências; é uma forma importante de a comunidade avaliar as hipóteses e a validade das afirmações" (p. 68, tradução nossa).

Na literatura, encontramos várias definições para "argumento" e "argumentação", fato que gera alguma confusão relativamente a ambos os termos (BERLAND; HAMMER, 2012; CAVAGNETTO, 2010; GARCIA-MILA et al., 2013). Para Sampson e Clark (2008) "o termo 'argumento' descreve os artefatos que um estudante ou um grupo de estudantes cria quando lhe é solicitado que indique e justifique afirmações ou explicações, ao passo que o termo 'argumentação' se refere ao processo de construção desses artefatos” (p. 448, tradução nossa).

Nesta linha de raciocínio, é importante deixar claro o nosso entendimento sobre argumentação. Primeiramente, a argumentação pode ser compreendida como uma ferramenta para a aprendizagem de Ciências, na medida em que se estabelece com os aprendizes uma relação social de troca de ideias; ou como uma ferramenta de compreensão do processo de aprendizagem de Ciências, através da análise da estrutura, qualidade e movimento do argu- 
mento. Em segundo lugar, a argumentação refere-se ao processo discursivo (oral ou escrito) apoiado por um argumento (componentes e artefatos) que surge durante as "etapas ou passos das atividades investigativas". São essas etapas: (1) apresentar um problema e refletir sobre ele; (2) elaborar hipóteses; (3) explicar o processo investigativo; (4) analisar e interpretar os dados; (5) concluir as atividades.

Uma vez definidos os termos 'argumento' e 'argumentação', apresentamos os quatros fundamentos essenciais acerca de como os alunos geram discussões no contexto da educação científica.

\section{II.2 Os fundamentos essenciais da argumentação no contexto da educação científica}

Para quem estuda a forma como os alunos geram discussões no contexto da educação científica e durante o desenvolvimento de atividades de investigação, organizamos esta fundamentação teórica em torno de quatro características do argumento, onde chamamos de fundamentos essenciais da argumentação no ensino de Ciências: (1) a estrutura ou a complexidade do argumento (ou seja, os componentes de um argumento); (2) a qualidade de um argumento (isto é, o que faz um argumento ser melhor que o outro); (3) o processo de movimento e progressão do argumento (ou seja, o processo de desenvolvimento do argumento); e (4) a construção social do argumento (ou seja, a influência do contexto social para o desenvolvimento do argumento). Estes elementos têm como objetivo proporcionar perspectivas teóricas subjacentes às estruturas, qualidades, progressões e aspectos sociais do argumento no contexto da educação científica.

\section{II.2.1 A Estrutura do Argumento}

A primeira característica do argumento é, sobretudo, a forma como surge organizado e estruturado nas falas dos participantes no processo argumentativo (OSBORNE et al., 2004). A análise das estruturas dos argumentos dos estudantes fornece informações sobre a forma e o tipo de raciocínio usados pelos alunos quando elaboram argumentos com base nas atividades científicas desenvolvidas (CLARK; SAMPSON, 2007). Organizamos este tópico apresentando alguns exemplos de trabalhos essenciais para compreender como pode o argumento ser estruturado.

O primeiro exemplo é o "Toulmin’s Argument Pattern - TAP” (Padrão Argumentativo de Toulmin) que influenciou (e ainda influencia) vários estudos sobre a estrutura da argumentação e o processo de ensino-aprendizagem. Toulmin (2003), versão mais atual para a obra The Uses of Argument de 1958, apresenta a distinção entre argumentos lógico-formais, usados em matemática, e a utilização de argumentos em contextos linguísticos.

Segundo Sasseron e Carvalho (2011), Toulmin preocupou-se em estabelecer uma interpretação estrutural da argumentação e o seu objetivo era mostrar que nem todos os argumentos podem ser enquadrados na forma "das premissas às conclusões". Para isso, Toulmin confere uma forma ao argumento esquematizado da seguinte maneira: 


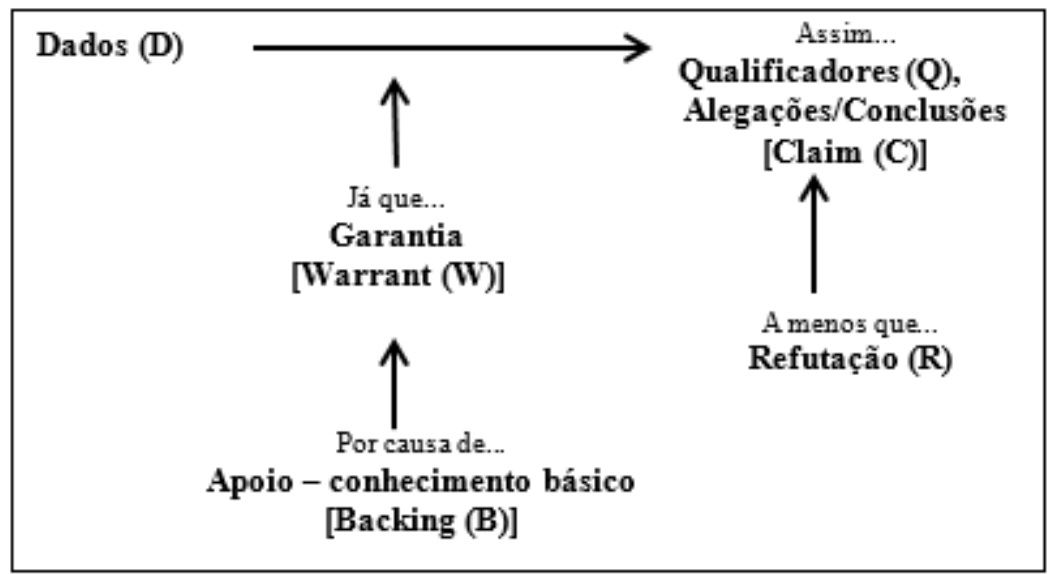

Fig. 1 -Esquema TAP (extraído de Sampson e Clark, 2008, p. 450, tradução nossa).

O modelo de Toulmin (Fig. 1) especifica os componentes da construção do pensamento a partir de dados para uma conclusão ou afirmação do conhecimento. Driver, Newton e Osborne (2000) resumem os principais componentes identificados por Toulmin no Quadro 1.

Quadro 1 - Características dos componentes TAP.

\begin{tabular}{|c|c|}
\hline Componentes TAP & Características \\
\hline Dados (D) & $\begin{array}{r}\text { Estes são os fatos aos quais os envolvidos no discurso argumentativo } \\
\text { recorrem para sustentar as suas alegações. }\end{array}$ \\
\hline $\begin{array}{c}\text { Alegações (afirmações } \\
\text { ou conclusões) (C) }\end{array}$ & Esta é a conclusão cujos méritos devem ser estabelecidos. \\
\hline Garantias (W) & $\begin{array}{c}\text { Estas são as razões (regras, princípios etc.) propostas para justificar as } \\
\text { ligações entre os dados e a afirmação de conhecimentos ou conclusão. }\end{array}$ \\
\hline $\begin{array}{c}\text { Apoio (conhecimento } \\
\text { básico) (B) }\end{array}$ & $\begin{array}{c}\text { Estas são as assunções básicas, geralmente tidas como as mais comuns, } \\
\text { que fornecem as justificações para garantias específicas. }\end{array}$ \\
\hline $\begin{array}{c}\text { Qualificadores (Q) } \\
\text { Refutações (R) }\end{array}$ & $\begin{array}{c}\text { Especificam as condições sob as quais a alegação pode ser tida por ver- } \\
\text { dadeira. Representam as limitações existentes acerca da alegação. }\end{array}$ \\
\hline Especificam as condições em que a afirmação não será verdadeira. \\
\hline
\end{tabular}

Fonte: Driver et al. (2000, p. 293, tradução nossa).

Embora seja muito utilizado, o modelo de Toulmin é alvo de restrições efetuadas por diversos investigadores, que propõem complementações para melhor adequação à realidade do ensino e da aprendizagem (CLARK; SAMPSON, 2007; DRIVER et al., 2000; JIMÉNEZALEIXANDRE; BUGALLO RODRÍGUEZ; DUSCHL, 2000; SAMPSON; CLARK, 2008; SASSERON, 2008). 
Driver et al. (2000) apontam limites para a utilização do modelo de Toulmin: (a) o padrão não considera o contexto da construção da argumentação; (b) frequentemente, partes da argumentação, como a garantia, não são explicitadas nos discursos, embora se encontrem implícitas; (c) o fluxo natural da conversação não se desenvolve necessariamente em sequência, dificultando a caracterização da argumentação em sala de aula; e (d) no ensino das ciências nem tudo se faz oralmente. Pelo contrário, recorre-se a diversas formas de linguagem semiótica para complementar a comunicação - gestos, manipulação de materiais, ilustrações e gráficos. Na revisão de Sampson e Clark (2008), surgem também restrições relativamente ao TAP, na medida em que existe uma "distinção fiável entre alegações, dados, provas e apoios [conhecimento básico], dado que os comentários feitos pelos estudantes podem ser frequentemente classificados em múltiplas categorias” (p. 451, tradução nossa).

Nos últimos anos, a partir destas dificuldades, começaram a surgir diferentes trabalhos que, mesmo utilizando o TAP como referencial, apresentam soluções de análise do argumento na sala de aula.

Um exemplo dessas soluções é o trabalho de Sasseron e Carvalho (2009, 2011, 2013) que buscaram compreender a forma como se processava a Alfabetização Científica entre alunos do ensino básico e que somente com o padrão de Toulmin não era possível de analisar as argumentações que ocorriam em sala de aula. Assim, Sasseron (2008) apresenta um paralelo entre as ideias apresentadas por Toulmin e os seus Indicadores da Alfabetização Científica (IAC) com três objetivos essenciais: (a) trabalhar com os dados de uma investigação; (b) identificar a estruturação do pensamento; (c) entender a situação analisada. O Quadro 2 vem caracterizar as dimensões e funcionalidades dos IAC.

Quadro 2 - Indicadores de Alfabetização Científica (IAC).

\begin{tabular}{|c|c|c|c|}
\hline Dimensões & Funcionalidade & IAC & Descrição \\
\hline \multirow{5}{*}{$\begin{array}{l}\text { Dimensão Es- } \\
\text { truturante }\end{array}$} & \multirow{3}{*}{$\begin{array}{l}\text { Indicadores } \\
\text { relacionados } \\
\text { com o tratamen- } \\
\text { to e análise dos } \\
\text { dados de uma } \\
\text { investigação }\end{array}$} & $\begin{array}{l}\text { Seriação de } \\
\text { Informações }\end{array}$ & $\begin{array}{l}\text { Bases para a ação investigativa. Podem } \\
\text { resultar de uma lista ou da relação dos da- } \\
\text { dos trabalhados ou com os quais se vá tra- } \\
\text { balhar. }\end{array}$ \\
\hline & & $\begin{array}{l}\text { Organização } \\
\text { de Informa- } \\
\text { ções }\end{array}$ & $\begin{array}{l}\text { Verifica-se quando preparamos os dados } \\
\text { existentes sobre o problema investigado. } \\
\text { Ocorre tanto no início da apresentação de } \\
\text { uma questão (pergunta ou problema de } \\
\text { investigação) quanto na retomada de uma } \\
\text { questão. }\end{array}$ \\
\hline & & $\begin{array}{l}\text { Classificação } \\
\text { de Informa- } \\
\text { ções }\end{array}$ & $\begin{array}{c}\text { Caracteriza os dados obtidos para ordenar } \\
\text { (organizar) os elementos com que se traba- } \\
\text { lha. }\end{array}$ \\
\hline & \multirow{2}{*}{$\begin{array}{l}\text { Indicadores } \\
\text { relacionados } \\
\text { com a obtenção } \\
\text { de dados e deli- }\end{array}$} & $\begin{array}{l}\text { Levantamento } \\
\text { de Hipóteses }\end{array}$ & $\begin{array}{l}\text { Suposições acerca de determinado tema } \\
\text { (podem surgir sob a forma de uma afirma- } \\
\text { ção ou de uma pergunta). }\end{array}$ \\
\hline & & Teste de Hipó- & Coloca à prova as suposições anteriormente \\
\hline
\end{tabular}




\begin{tabular}{|c|c|c|c|}
\hline Dimensões & Funcionalidade & IAC & Descrição \\
\hline & $\begin{array}{l}\text { mitação de vari- } \\
\text { áveis }\end{array}$ & teses & $\begin{array}{l}\text { levantadas (pode ocorrer quer face à mani- } \\
\text { pulação direta de objetos quer ao nível das } \\
\text { ideias). }\end{array}$ \\
\hline \multirow{5}{*}{$\begin{array}{c}\text { Dimensão } \\
\text { Epistemológica }\end{array}$} & \multirow{2}{*}{$\begin{array}{l}\text { Indicadores para } \\
\text { estruturação do } \\
\text { pensamento }\end{array}$} & $\begin{array}{l}\text { Raciocínio } \\
\text { Lógico }\end{array}$ & $\begin{array}{l}\text { Compreende o modo como as ideias são } \\
\text { desenvolvidas e apresentadas. Está direta- } \\
\text { mente relacionado com a forma como o } \\
\text { pensamento é exposto. }\end{array}$ \\
\hline & & $\begin{array}{l}\text { Raciocínio } \\
\text { Proporcional }\end{array}$ & $\begin{array}{l}\text { Caracteriza a forma como se estrutura o } \\
\text { pensamento e como as variáveis se relacio- } \\
\text { nam entre si. }\end{array}$ \\
\hline & \multirow{3}{*}{$\begin{array}{l}\text { Indicadores de } \\
\text { relação entre } \\
\text { variáveis e in- } \\
\text { formações }\end{array}$} & Justificativa & $\begin{array}{l}\text { Quando numa qualquer afirmação é apre- } \\
\text { sentada uma garantia para aquilo que é } \\
\text { proposto. }\end{array}$ \\
\hline & & Previsão & $\begin{array}{l}\text { É explicitada quando se afirma uma ação } \\
\text { e/ou fenômeno associado a determinados } \\
\text { acontecimentos. }\end{array}$ \\
\hline & & Explicação & $\begin{array}{c}\text { Quando se procura relacionar informações e } \\
\text { hipóteses já levantadas (pode ser acompa- } \\
\text { nhada por uma justificativa e uma previ- } \\
\text { são). }\end{array}$ \\
\hline
\end{tabular}

Fonte: Sasseron e Carvalho (2009, 2013) - modificado.

Complementarmente, Sasseron e Carvalho (2013) propõem uma análise na estrutura das respostas dos alunos e nas ações do professor, de modo a fomentar as discussões ocorridas na sala de aula. Para a análise da estrutura das falas dos alunos, as autoras utilizam os IAC e para as ações do professor, elas propõem novas categorias, os propósitos do professor, que se relacionam diretamente com a promoção das AIEC e da argumentação em sala de aula (Quadro 3).

Quadro 3 - Propósitos e ações do professor na promoção da construção de entendimento de ideias científicas.

\begin{tabular}{|c|c|c|}
\hline Propósitos do professor & Ações do professor & $\begin{array}{c}\text { Indicadores de AC expressos } \\
\text { pelos alunos }\end{array}$ \\
\hline $\begin{array}{c}\text { Recuperação de ideias já dis- } \\
\text { cutidas }\end{array}$ & $\begin{array}{c}\text { Referência a ideias previamente } \\
\text { trabalhadas e/ou experiências } \\
\text { prévias dos alunos }\end{array}$ & $\begin{array}{c}\text { Organização, seriação e classi- } \\
\text { ficação de informações }\end{array}$ \\
\hline Proposta de um problema & $\begin{array}{c}\text { Problematização de uma situa- } \\
\text { ção }\end{array}$ & $\begin{array}{c}\text { Levantamento de hipóteses, } \\
\text { teste de hipóteses }\end{array}$ \\
\hline Delimitação de variáveis & $\begin{array}{c}\text { Descrição e caracterização do } \\
\text { fenômeno e/ou de objetos }\end{array}$ & $\begin{array}{c}\text { Organização e seriação de } \\
\text { informações }\end{array}$ \\
\hline
\end{tabular}




\begin{tabular}{|c|c|c|}
\hline Propósitos do professor & Ações do professor & $\begin{array}{c}\text { Indicadores de AC expressos } \\
\text { pelos alunos }\end{array}$ \\
\hline Reconhecimento de variáveis & $\begin{array}{c}\text { Dar nome às categorias advindas } \\
\text { da caracterização }\end{array}$ & Classificação de informações \\
\hline $\begin{array}{c}\text { Construção de relação entre } \\
\text { variáveis }\end{array}$ & Entrecruzamento de informações & $\begin{array}{c}\text { Levantamento de hipóteses, } \\
\text { explicação, previsão, justifica- } \\
\text { ção }\end{array}$ \\
\hline
\end{tabular}

Fonte: Sasseron e Carvalho (2013, p. 176).

Para Sasseron e Carvalho (2013), a estruturação do argumento está associada aos propósitos do professor em forma de planejamento (etapas em que se começa a estabelecer os elementos constituintes do argumento), às suas ações (referem-se especificamente ao conteúdo e despontam a possibilidade de se examinar a qualidade das ideias em discussão) e ao trabalho dos alunos por meio dos IAC (cujas ideias correspondem à construção dos elementos constitutivos do argumento) (Quadro 3). Ao analisarmos os IAC de Sasseron (2008), percebemos que eles não discutem os comentários emotivos que fazem parte da argumentação racional e que dão enfoque à veracidade e à autoridade do pensamento do aluno e também não explicita os comentários dos alunos que se desviam do assunto principal e que muitas vezes estão presentes no discurso argumentativo.

Um segundo exemplo referente à estrutura da argumentação é o trabalho de Bellucco e Carvalho (2014) que, a partir de uma revisão da literatura sobre argumentação e aprendizagem, identificaram um conjunto de categorias do processo argumentativo em ensino de Ciências designado por "aspectos campo-dependentes", definido no Quadro 4.

Quadro 4 - Características campo-dependentes da argumentação científica.

\begin{tabular}{|c|c|}
\hline $\begin{array}{l}\text { Características } \\
\text { Campo- } \\
\text { Dependentes }\end{array}$ & Descrição \\
\hline Seriação & $\begin{array}{c}\text { Lista de dados trabalhados ou a trabalhar. Estabelece as bases para a investi- } \\
\text { gação. }\end{array}$ \\
\hline $\begin{array}{l}\text { Classificação e or- } \\
\text { ganização de infor- } \\
\text { mações }\end{array}$ & $\begin{array}{c}\text { Trata-se da busca por similaridades num arranjo de informações, podendo } \\
\text { criar-se hierarquias entre elas. }\end{array}$ \\
\hline $\begin{array}{l}\text { Levantamento e teste } \\
\text { de hipóteses }\end{array}$ & Suposições sobre um tema em estudo que são colocadas à prova. \\
\hline Justificativa & $\begin{array}{c}\text { Cria a base para sustentar uma alegação que leva a uma conclusão. Poderá } \\
\text { ser o uso de definição, o apelo à analogia ou a comparações, exemplos, atri- } \\
\text { butos, consistência com outros conhecimentos - incluindo a experiência e a } \\
\text { metafísica - e plausibilidade. }\end{array}$ \\
\hline Explicação & Relaciona informações e hipóteses, geralmente após a uma justificativa. \\
\hline Previsão & Antecipar ações e/ou fenômenos relacionando acontecimentos. \\
\hline
\end{tabular}




\begin{tabular}{|c|c|}
\hline $\begin{array}{c}\text { Características } \\
\text { Campo- } \\
\text { Dependentes }\end{array}$ & Descrição \\
\hline Abdução & $\begin{array}{c}\text { Uso de uma hipótese/regra como justificativa para explicar um conhecimento } \\
\text { novo, de forma a criar dados para sustentar uma conclusão. }\end{array}$ \\
\hline Dedução & Raciocínio do geral para o particular. \\
\hline Indução & Conclusão apoiada numa inferência, das partes para o todo. \\
\hline $\begin{array}{c}\text { Raciocínio lógico e } \\
\text { proporcional }\end{array}$ & $\begin{array}{c}\text { Forma como o pensamento é estruturado e como se relacionam as variáveis } \\
\text { no mesmo. }\end{array}$ \\
\hline
\end{tabular}

Fonte: Bellucco e Carvalho (2014, p. 34).

Para Bellucco e Carvalho (2014), as características campo-dependentes da argumentação, destacadas no Quadro 4, deverão perpassar em maior ou menor grau sem a necessidade de intervenções extra do professor por todas as etapas do raciocínio científico: a) elaboração e testes de hipóteses, em que o conhecimento prévio é tido como hipótese de pesquisa na resolução do problema; b) argumentação; c) solução do problema, produzindo uma explicação; d) construção do raciocínio proporcional do tipo "se, então, portanto", o que envolve a seleção e a relação de variáveis relevantes face à solução do problema e à necessidade de uma nova palavra/conceito. Por exemplo, ao usar o conhecimento prévio como hipótese de pesquisa, um estudante pode recorrer a um raciocínio abdutivo que tente explicar e justificar a resposta ao problema proposto. Por outro lado, ao manipular uma experiência (dispositivo do tipo handson), no processo de reconhecimento das variáveis envolvidas no fenômeno, o aluno procura enumerar, classificar e organizar as informações observadas com base no seu arcabouço teórico.

Uma limitação das características campo-dependentes da argumentação científica refere-se ao fato de que, mesmo que as categorias de Bellucco e Carvalho (2014) tenham origem em diferentes estudos, não encontramos novos elementos, ou seja, podemos encontrar nas características campo-dependentes (Quadro 4) os Indicadores de Alfabetização Científica de Sasseron e Carvalho (2013): seriação, classificação e organização de informações, justificativa, explicação, previsão e raciocínio lógico e proporcional, bem como as Operações Epistêmicas de Jiménez-Aleixandre et al. (2000): abdução e dedução.

O último exemplo, referente à estrutura do argumento, é o esquema de codificação de base e hierarquia para a classificação da estrutura argumentativa de Clark e Sampson (2007). $\mathrm{O}$ estudo destes autores centra-se no apoio à argumentação científica em sala de aula através de um sistema de discurso on-line personalizado, designado "Personally-seeded discussions", que apoia a aprendizagem e colaboração através de uma estrutura de atividades que contrasta com as próprias ideias dos alunos, visando envolvê-los no discurso argumentativo de atividades investigativas em ensino de Ciências. 
Este estudo explora a eficácia da abordagem "Personally-seeded discussions", baseada sobre o esquema de codificação desenvolvido por Erduran et al. (2004) ${ }^{2}$, que analisa a estrutura do argumento dos alunos segundo a perspectiva de Toulmin (2003).

O esquema de codificação de Clark e Sampson (2007) utiliza os três códigos básicos de Erduran et al. (2004) para os comentários dos alunos: (1) afirmação (claim), (2) fundamentos (grounds), e (3) refutação (rebuttal). Os autores adicionaram quatro códigos para caracterizar as operações epistemológicas das comunicações e interações dos alunos no ambiente online: (4) apoio, (5) inquirição (questões), (6) apelo emotivo, e (7) comentários extra-tarefa. O esquema de codificação de Clark e Sampson (2007) é representado no Quadro 5.

Quadro 5 - Esquema de codificação de base e hierarquia para classificação da estrutura argumentativa.

\begin{tabular}{|c|c|}
\hline $\begin{array}{l}\text { Operações epis- } \\
\text { temológicas }\end{array}$ & Descrição \\
\hline $\begin{array}{l}\text { Afirmação } \\
\text { (Claim) }\end{array}$ & $\begin{array}{l}\text { A afirmação criada por cada grupo de estudantes através da interface "criador } \\
\text { de princípios" é colocada como discussão inicial. Grupo de alunos também } \\
\text { podem apresentar afirmações opostas dentro de um episódio nas discussões on- } \\
\text { line (por exemplo: "Todos os objetos permanecerão com diferentes temperatu- } \\
\text { ras no mesmo ambiente"). }\end{array}$ \\
\hline $\begin{array}{l}\text { Fundamentos } \\
\text { (Grounds) }\end{array}$ & Incluem dados, garantias e bases de sustentação (conhecimento básico). \\
\hline $\begin{array}{l}\text { Refutação } \\
\text { (Rebuttal) } \\
\end{array}$ & Inclui ataques aos fundamentos de uma afirmação ou diretamente à afirmação. \\
\hline Apoio & $\begin{array}{c}\text { O apoio engloba os comentários que sustentam as alegações ou as refutações } \\
\text { iniciais. }\end{array}$ \\
\hline Questões & $\begin{array}{c}\text { As perguntas incluem comentários que carecem da clarificação de comentários } \\
\text { anteriores ou indagam sobre o posicionamento de outros grupos face a uma } \\
\text { determinada questão. }\end{array}$ \\
\hline Apelo emotivo & $\begin{array}{l}\text { Ocasionalmente, os comentários não fazem parte da argumentação racional, } \\
\text { sendo essencialmente emotivos no conteúdo. Porém, dão enfoque à veracidade } \\
\text { e à autoridade. }\end{array}$ \\
\hline $\begin{array}{l}\text { Comentários } \\
\text { extra tarefa }\end{array}$ & Por vezes, os comentários também se desviam do assunto principal. \\
\hline
\end{tabular}

Fonte: Clark e Sampson (2007, p. 264) adaptado pelos autores.

Clark e Sampson (2007) usaram os códigos do Quadro 5 para classificar os argumentos dos alunos segundo a hierarquia da estrutura e qualidade da argumentação de Erduran et al. (2004). As operações epistemológicas que destacamos neste instrumento estão relacionados ao "apelo emotivo" e "comentários extra tarefa" que não aparecem nos exemplos citados anteriormente.

\footnotetext{
2 O estudo de Erduran et al. (2004) será melhor apresentado no tópico referente à Qualidade do Argumento e através do Quadro 7.
} 
Vale destacar que, os exemplos citados anteriormente tiveram somente o objetivo de ilustrar o primeiro fundamento essencial da argumentação científica referente à sua estrutura, porém outros trabalhos poderiam ser citados, como por exemplo, as Operações Epistêmicas (OE) de Jiménez-Aleixandre et al. (2000) - dedução, causalidade, definição, classificação, consistência e plausibilidade, apelo a analogias e a exemplos etc. -, utilizadas para analisar a argumentação dos alunos juntamente com o padrão de Toulmin.

\section{II.2.2 A Qualidade do Argumento}

A segunda característica do argumento ou segundo fundamento essencial da argumentação no ensino de Ciências consiste em identificar bons argumentos. Neste sentido, alguns estudos procuram caracterizar a qualidade do argumento por estruturas qualitativas (SAMPSON; BLANCHARD, 2012; SAMPSON; CLARK, 2006), outros por níveis hierárquicos (ERDURAN et al., 2004; GARCIA-MILA et al., 2013; OSBORNE et al., 2004), ou seja, apresentam uma estrutura ou hierarquia de códigos para classificar a qualidade do argumento (DRIVER et al., 2000; SASSERON; CARVALHO, 2009).

Apoiado no Padrão do Argumento de Toulmin (2003) (TAP), Erduran et al. (2004) define a qualidade da argumentação em termos de presença e natureza das refutações manifestadas entre os estudantes. Assim, para Erduran et al. (2004) “compreender a presença de uma refutação como indicador expressivo da qualidade da argumentação e a forma como contradiz os argumentos de terceiros obriga ambos os participantes a avaliar a validade e a força desse argumento" (p. 07, tradução nossa).

Para exemplificar, podemos citar alguns trabalhos que apresentam estruturas qualitativas e/ou níveis hierárquicos e que poderão ser orientadores para verificar a qualidade de um argumento.

Um exemplo de estruturas qualitativas é o trabalho de Sampson e Blanchard (2012) que apresentam um modelo que descreve os componentes de um argumento no ensino de $\mathrm{Ci}$ ências (afirmação, evidência e análise racional) e critérios de avaliação da qualidade de um argumento no ensino de Ciências (Fig. 2).

Este modelo destaca três critérios a fim de avaliar a estrutura/qualidade de um argumento (Fig. 2): 1) Critérios empíricos: incluem normas, a forma como a "afirmação" se encaixa com todas as evidências disponíveis, a adequação das evidências contidas no argumento, bem como a qualidade geral da evidência; b) Critérios teóricos: referem-se aos padrões de natureza conceitual, que incluem julgamentos sobre a utilidade da conclusão, a sua adequação e a consistência da conclusão com outras teorias, leis ou modelos; c) Critérios de análise: são usados para avaliar a qualidade geral da linha de raciocínio (por exemplo, análise de correlação e/ou hipotético-dedutivo) e para determinar se a análise e a interpretação dos dados são coerentes. A natureza dos componentes que constituem um argumento científico e que conta 
como qualidade e como resultado, depende da disciplina e até da área de investigação (SAMPSON; BLANCHARD, 2012, p. 1123).

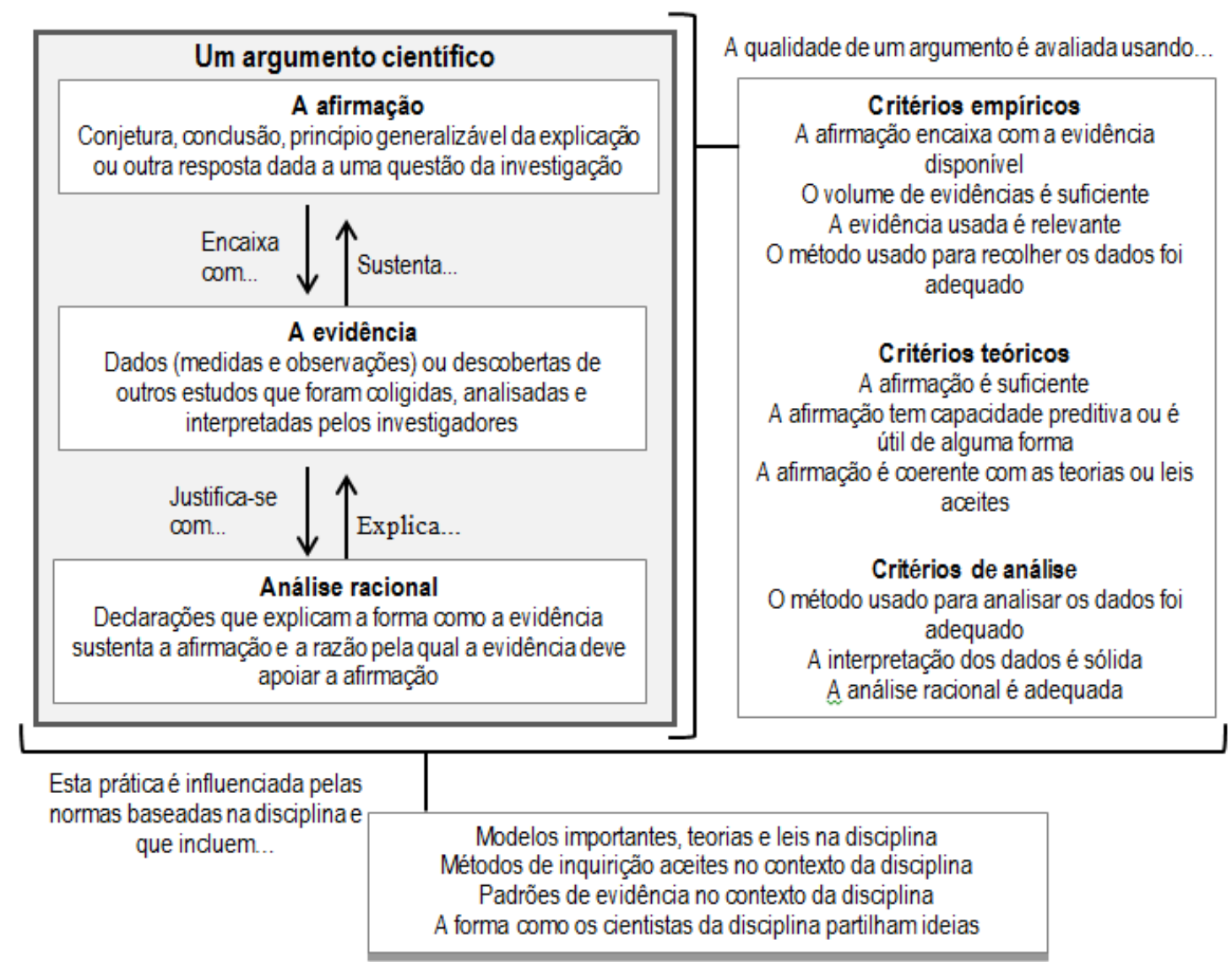

Fig. 2 - Alguns critérios qualitativos que podem ser usados para avaliar a qualidade de um argumento científico (extraído de Sampson e Blanchard, 2012, p. 1124, tradução nossa).

O trabalho de Sampson e Clark (2006) é outro exemplo de estrutura qualitativa e que vem complementar os critérios da qualidade de um argumento no ensino de Ciências de Sampson e Blanchard (2012) com a proposição de cinco critérios epistêmicos:

Quadro 6 - Critérios epistêmicos para analisar a qualidade do argumento.

\begin{tabular}{|c|c|}
\hline Critérios epistemológicos & Descrições \\
\hline $\begin{array}{c}\text { 1. Examinar a natureza e a quali- } \\
\text { dade da afirmação de conheci- } \\
\text { mento }\end{array}$ & $\begin{array}{c}\text { Os métodos analíticos devem centrar-se nas formas de afirma- } \\
\text { ção feitas pelos estudantes e na capacidade para coordenar as } \\
\text { afirmações com as provas disponíveis. }\end{array}$ \\
\hline $\begin{array}{c}\text { 2. Avaliar como (ou se) a afirma- } \\
\text { ção se justifica }\end{array}$ & $\begin{array}{c}\text { Os estudantes necessitam aprender a fornecer evidências empí- } \\
\text { ricas, mas eles também necessitam aprender que tipos de provas } \\
\text { são necessários para garantir um argumento. }\end{array}$ \\
\hline 3. Verificar se uma afirmação & Os estudantes tendem a não se concentrar nos padrões existen- \\
\hline
\end{tabular}




\begin{tabular}{|c|c|}
\hline $\begin{array}{c}\text { explica todas as evidências dispo- } \\
\text { níveis }\end{array}$ & $\begin{array}{c}\text { tes nos dados, dando antes prioridade às evidências avulsas que } \\
\text { apoiam crenças pessoais. }\end{array}$ \\
\hline $\begin{array}{c}\text { 4. Verificar como (ou se) a argu- } \\
\text { mentação tenta eliminar alternati- } \\
\text { vas }\end{array}$ & $\begin{array}{c}\text { Um fenômeno poderá ser explicado por mais do que uma afir- } \\
\text { mação, os estudantes precisam de aprender a desafiar a fragili- } \\
\text { dade de explicações alternativas. }\end{array}$ \\
\hline $\begin{array}{c}\text { 5. Verificar como as referências } \\
\text { epistemológicas são usadas para } \\
\text { coordenar as afirmações e as evi- } \\
\text { dências }\end{array}$ & $\begin{array}{c}\text { Os estudantes necessitam de aprender como justificar/avaliar a } \\
\text { forma como as evidências são reunidas e interpretadas, já que } \\
\text { os estudantes não verificam o planejamento das investigações } \\
\text { ou os métodos usados para obter evidências. }\end{array}$ \\
\hline
\end{tabular}

Fonte: Sampson e Clark (2006, p. 658-660), tradução nossa.

Os níveis qualitativos podem possibilitar, em alguns momentos, à generalização e subjetividade da qualidade do argumento dos participantes. Essa limitação pode ser decorrente do caráter descritivo e narrativo de alguns instrumentos e que por vezes, tem dificuldade em caracterizar o argumento de uma determinada população, da qual seria representativa.

Diferente das estruturas qualitativas, o Quadro 7 apresenta um exemplo de níveis hierárquicos para avaliação da qualidade do argumento em termos de cinco níveis de argumentação, proposto por Erduran et al. (2004) e usado por Garcia-Mila et al. (2013), Clark e Sampson (2007), Osborne et al. (2004) e Simon et al. (2012).

Quadro 7 - Quadro analítico usado para avaliar a qualidade da argumentação.

\begin{tabular}{|c|c|}
\hline Nível & Descrições \\
\hline Nível 1 & $\begin{array}{c}\text { A argumentação consiste nos argumentos que são uma simples afirmação versus uma } \\
\text { contra-afirmação ou uma afirmação versus outra afirmação. }\end{array}$ \\
\hline Nível 2 & $\begin{array}{c}\text { A argumentação encerra argumentos que consistem numa afirmação versus outra afir- } \\
\text { mação que inclui dados, provas ou apoios (bases de sustentação), mas não contém } \\
\text { refutações. }\end{array}$ \\
\hline Nível 3 & $\begin{array}{c}\text { A argumentação possui argumentos com várias afirmações ou contra-afirmações que } \\
\text { apresentam dados, provas ou apoios (bases de sustentação) com a ocasional refutação } \\
\text { frágil. }\end{array}$ \\
\hline Nível 4 & $\begin{array}{c}\text { A argumentação revela argumentos com a pretensão de ter uma refutação claramente } \\
\text { identificável. Tal argumento poderá incluir várias afirmações e contra afirmações. }\end{array}$ \\
\hline Nível 5 & A argumentação exibe uma extensa argumentação com mais de uma refutação. \\
\hline
\end{tabular}

Fonte: Erduran et al. (2004, p. 16), tradução nossa.

Para Erduran et al. (2004), "quando as crianças se envolvem num processo e se apoiam mutuamente em termos de elevada qualidade argumentativa, a interação entre as dimensões pessoal e social promove a reflexão, a posse e o desenvolvimento do conhecimento, crenças e valores" (p. 03). 
Segundo Clark e Sampson (2007), o esquema de codificação de Erduran et al. (2004) centra-se na qualidade de argumentação dialógica nas discussões com toda a turma. A fim de avaliar a qualidade deste tipo de argumentação, Erduran et al. (2004) concentraram-se apenas na estrutura do argumento e na identificação dos componentes estruturais presentes nos argumentos dos alunos, ou seja, no uso de afirmações, alegações opostas, refutações e fundamentos (com base no modelo de Toulmin). Para Clark e Sampson (2007), Erduran et al. (2004) colapsaram os elementos "dados, provas e apoios" de Toulmin em um único código - "fundamentos" (que são os fatos específicos invocados para sustentar uma dada afirmação), devido às dificuldades práticas de diferenciação entre estes componentes de argumentação.

Os estudos que caracterizam a qualidade do argumento em níveis hierárquicos (CLARK; STEGMANN; WEINBERGER; MENEKSE; ERKENS, 2007; ERDURAN et al., 2004; GARCIA-MILA et al., 2013; OSBORNE et al., 2004; SIMON et al., 2012) veem os argumentos mais simples como os que consistem numa afirmação e que, ao mesmo tempo, são importantes, na medida em que é a partir deles que se dá o primeiro passo para iniciar o processo de criação de diferentes níveis da qualidade do argumento. Além disso, estes estudos sugerem que os professores sejam capazes de identificar a evolução dos níveis discursivos dos alunos e de expor as suas limitações (por exemplo, a falta de justificativa no argumento). Por isso, o segundo nível é formado por argumentos acompanhados de afirmações que contenham dados ou garantias, e o terceiro, formado por argumentos que consistem em afirmações ou contra afirmações, dados, justificativas e refutações. Verifica-se nos trabalhos citados no início do parágrafo que os argumentos com refutações apresentam, no entanto, melhor qualidade do que aquelas que as não têm.

Podemos dizer que "o critério para avaliar a qualidade dos argumentos incluiu a profundidade das explicações dadas, a elaboração das afirmações ou dos fundamentos mencionados, a adequação de vários exemplos usados como justificativa e a presença ou ausência de contra-argumentos para refutação de ideias opostas" (CHIN; OSBORNE, 2010, p. 891, tradução nossa).

\section{II.2.3 O processo de movimento e progressão do argumento}

A terceira característica ou terceiro fundamento essencial da argumentação está relacionado com o seu processo de estímulo, movimento e progressão. Existe uma necessidade de planejamento por parte do professor na condução de ações tendo em vista o desenvolvimento da argumentação e das capacidades essenciais dos alunos para que o discurso em sala de aula aconteça (CHIN; OSBORNE, 2010; CLARK; SAMPSON, 2007; OSBORNE et al., 2004). Quando se estabelece uma interação argumentativa na sala de aula, o discurso apresenta um movimento (BERLAND; REISER, 2011; DRIVER et al., 2000) e uma progressão (BERLAND; MCNEILL, 2010) que caracterizam o processo argumentativo e o desenvolvimento da aprendizagem dos alunos. 
Na perspectiva do processo de movimento e progressão do argumento podemos citar, por exemplo, a criação de um ciclo argumentativo nas discussões científicas de sala de aula, como propõe Sasseron e Carvalho $(2011,2013)$. O ciclo argumentativo destas autoras analisa tanto o surgimento de IAC, nas aulas de Ciências, como a construção de argumentos pelo professor e pelos alunos, ou seja, o ciclo "teria início com a recuperação de ideias já discutidas na sala de aula, aproveitando as informações que os alunos já possuíam” (p. 251).

Neste sentido, para ilustrar o fundamento sobre o movimento e progressão do argumento, podemos citar o trabalho de Berland e Reiser (2011) que apresenta uma análise sobre o movimento discursivo (discourse moves). Segundo estes autores, esses movimentos surgem a partir das descrições do processo argumentativo em sala de aula em que os alunos estão envolvidos num processo de sensemaking [construção de sentidos] colaborativo a partir da análise estrutural do argumento de Toulmin (2003). Através deste processo, Berland e Reiser (2011) identificaram cinco características do discurso como sendo a chave para a argumentação científica. No discurso argumentativo, os estudantes "constroem afirmações e defendem as suas próprias afirmações e as de terceiros. Escutam e respondem às afirmações de terceiros. Protegem-se questionando essas afirmações. Escutam e respondem às afirmações uns dos outros e defendem-se avaliando-as, criticando-as e, simultaneamente, corrigindo as suas próprias afirmações e as de terceiros" (BERLAND; REISER, 2011, p. 199, tradução nossa). As palavras em itálico indicam as principais ações de cada movimento do discurso. Estes "movimentos do discurso" estão relacionados com os objetivos de sensemaking e persuasão, caracterizando-se pelas várias maneiras que o discurso em sala de aula pode estar envolvido nestes objetivos.

A Fig. 3 resume essa relação. Por exemplo, dois movimentos discursivos relacionamse diretamente com o objetivo de persuasão: a) defesa de uma declaração; e b) avaliação e crítica dos argumentos. Ambos os movimentos de discurso implicam envolvimento na persuasão, já que demonstram por que razão um pedido é mais persuasivo do que outro. Além disso, o objetivo de sensemaking envolve três movimentos de discurso: a) construção de uma declaração; b) questionamento e defesa das declarações; e c) revisão das declarações.

No diagrama da Fig. 3, "dar atenção aos outros" está compartilhado por ambos os objetivos (sensemaking e persuasão), ou seja, um aluno pode ouvir outras ideias em qualquer desses objetivos. No entanto, essa atenção envolve movimentos diferentes do discurso, dependendo do objetivo da interação. Quando um aluno estiver concentrado em sensemaking, ele poderá questionar as ideias dos outros, ao passo que a persuasão está mais relacionada com a avaliação e crítica de ideias. 


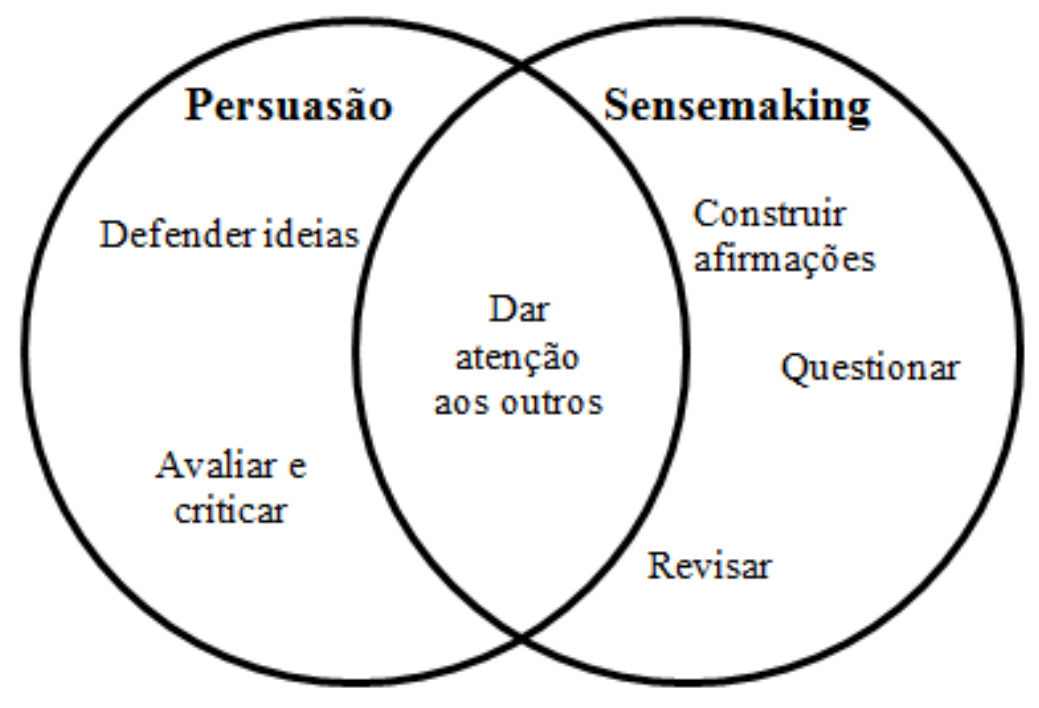

Fig. 3 - Associação das alterações discursivas da argumentação científica aos objetivos da persuasão e do sensemaking (extraído de Berland e Reiser, 2011, p. 200, tradução nossa).

Berland e Reiser (2011) sugerem que as diferentes configurações deste modelo não representam sobreposições, mas diferentes interpretações de argumentação, além de verificar que cada turma de alunos pode possuir objetivos distintos durante o processo argumentativo. É igualmente importante destacar que este movimento discursivo pode mudar segundo o conteúdo científico trabalhado e dependendo da forma como o professor conduz a argumentação.

Podemos também resgatar, de forma resumida, outros trabalhos que caracterizaram este fundamento, como por exemplo, as três dimensões de uma progressão de aprendizagem de Berland e Mcneill (2010): 1) Contexto instrucional; 2) Produtos argumentativos: e 3) Processo argumentativo. Os padrões de interações do discurso entre professores e alunos na sala de aula, por Mortimer e Scott (2003): I-R-A-F (Iniciação - Resposta - Avaliação - Feedback). E por fim, as estratégias para apoiar um processo argumentativo por Osborne et al. (2004): 1) lista de tópicos para argumentação; 2) pequenos grupos; 3) modelos de escrita; 4) role-plays; e 5) apresentações de grupo. Numa perspectiva de desenvolvimento, movimento e progressão do argumento, estes exemplos, em forma de atividades e ações, são importantes, na medida em que incentivam o uso do argumento seguido por desafios críticos e atividades (escrita, discussão e apresentação de ideias) que podem ser alteradas de acordo com o público de alunos, além de, também, serem essenciais para o desenvolvimento de capacidades na construção e defesa do argumento.

\section{II.2.4 A construção social do Argumento}

O último fundamento essencial da argumentação está relacionado com a construção social do argumento, ou seja, assumimos que a argumentação é uma atividade social (BER- 
LAND; MCNEILL, 2010; CHIN; OSBORNE, 2010; DRIVER et al., 2000; JIMÉNEZALEIXANDRE et al., 2000; OSBORNE et al., 2004) e que o conhecimento científico, enquanto construção social é, portanto, provisório (DRIVER et al., 2000).

Para Chin e Osborne (2010), a argumentação, num contexto social, "exige que os estudantes respondam às afirmações de terceiros com argumentos e contra-argumentos próprios, construindo explanações, levantando questões e refutando ideias alternativas" (p. 231, tradução nossa).

Algumas investigações (BERLAND; HAMMER, 2012; MORTIMER; SCOTT, 2003) têm adotado a perspectiva teórica associada à corrente sócio-histórica ou sociocultural de Vygotsky (1980, 1986), com enfoque no processo de compreensão da construção de significados, criados no contexto da interação social e interiorizados pelos indivíduos. Assim, as perspectivas cognitivistas sobre a argumentação forneceram uma importante base teórica sobre os processos e resultados cognitivos e socio cognitivos do cruzamento da argumentação com a aprendizagem (BRICKER; BELL, 2008).

Para um grupo de trabalhos (BERLAND; MCNEILL, 2010; MORTIMER; SCOTT, 2003; SCOTT; MORTIMER, 2005), o desenvolvimento de um argumento científico requer uma interação social com os pares (alunos-professor-especialistas) num contexto de sala de aula. Ou seja, o discurso argumentativo exige que os participantes interajam com as ideias dos outros em diferentes níveis e desenvolvimento de argumentação (ver tópicos sobre a qualidade e movimento da argumentação). No entanto, Berland e Mcneill (2010) e Berland e Reiser (2011) apontam que estudos sobre a argumentação revelam um conflito com o processo social da argumentação científica, ou seja, a interação em sala de aula caracteriza-se por ações do tipo I-R-A: o professor Inicia uma interação através da colocação de uma pergunta, um aluno Responde à questão e o professor Avalia a resposta dada.

Neste sentido, podemos citar os trabalhos de Mortimer e Scott (2003) e Scott e Mortimer (2005) que apresentam uma ferramenta analítica, ou um sistema de referência, para a conversa de sala de aula, em particular sobre a forma pela qual os diferentes tipos de interação entre professores e alunos contribuem para a construção de significados e da aprendizagem (Quadro 8). O desenvolvimento do referencial destes trabalhos não se baseia no padrão de Toulmin, mas na teoria sociocultural de Vygostsky e na linguagem social de Bakhtin (MORTIMER ; SCOTT, 2003). Alguns pontos fundamentais para o ensino de Ciências emergem da análise destes referenciais, particularmente em relação ao que os autores identificam como o aspecto central da "abordagem comunicativa".

A estrutura analítica da ferramenta de Mortimer e Scott (2003) baseia-se em cinco aspectos inter-relacionados que se centram no papel do professor (e não do aluno) e são agrupados em termos de focos do ensino, abordagem e ações: 
Quadro 8 - Aspectos da estrutura de análise das interações sociais e a produção de significados em aulas de Ciências por Mortimer e Scott (2003).

\begin{tabular}{|c|c|c|}
\hline $\begin{array}{l}\text { Papel do } \\
\text { professor }\end{array}$ & $\begin{array}{l}\text { Aspectos de Aná- } \\
\text { lise }\end{array}$ & Elementos característicos \\
\hline \multirow[t]{2}{*}{$\begin{array}{l}\text { Focos de } \\
\text { ensino }\end{array}$} & $\begin{array}{l}\text { 1. Intensões do } \\
\text { professor }\end{array}$ & $\begin{array}{c}\text { Criar um problema. } \\
\text { Explorar a visão dos estudantes. } \\
\text { Introduzir e desenvolver a 'estória científica' } \\
\text { Conduzir os estudantes no trabalho com as ideias científicas, } \\
\text { dando apoio ao processo de internalização. } \\
\text { Conduzir os estudantes na aplicação das ideias científicas e na } \\
\text { expansão do seu uso, transferindo para estes, progressivamente, } \\
\text { o controle e a responsabilidade por tal uso. } \\
\text { Manter a narrativa: sustentar o desenvolvimento da 'estória cien- } \\
\text { tífica'. }\end{array}$ \\
\hline & 2. Conteúdo & $\begin{array}{c}\text { Descrição } \\
\text { Explicação } \\
\text { Generalização } \\
\end{array}$ \\
\hline Abordagem & $\begin{array}{l}\text { 3. Abordagem } \\
\text { Comunicativa }\end{array}$ & $\begin{array}{c}\text { Interativa/dialógica (I/D) } \\
\text { Não-interativa/ dialógica (NI/D) } \\
\text { Interativa/ de autoridade (I/A) } \\
\text { Não-interativa/ de autoridade (NI/A) }\end{array}$ \\
\hline \multirow[b]{2}{*}{ Ações } & $\begin{array}{l}\text { 4. Padrões de } \\
\text { interaçã̃o }\end{array}$ & $\begin{array}{c}\text { I - Iniciação do professor } \\
\text { R - Resposta do aluno } \\
\text { A - Avaliação do professor } \\
\text { P - Prosseguimento da fala do aluno } \\
\text { F-Feedback para o aluno melhor elaborar a sua fala. }\end{array}$ \\
\hline & $\begin{array}{l}\text { 5. Intervenções do } \\
\text { professor }\end{array}$ & $\begin{array}{c}\text { Dar forma aos significados } \\
\text { Selecionar significados } \\
\text { Marcar significados-chave } \\
\text { Partilhar significados } \\
\text { Verificar o entendimento dos estudantes } \\
\text { Rever o progresso da estória científica }\end{array}$ \\
\hline
\end{tabular}

Fonte: Mortimer e Scott (2003) (adaptação dos autores).

De acordo com Mortimer e Scott (2003), a ênfase dada à produção de significados na sala de aula recai no foco de ensino desempenhado pelo professor, na sua tarefa de tornar disponível a visão da natureza da ciência, diferenciá-la de outras visões e dar apoio à construção de significados pelos alunos.

Relativamente à abordagem comunicativa, os autores consideram que existe uma tensão entre discurso dialógico e discurso de autoridade, que podem considerar-se casos extremos da abordagem comunicativa. Nesta concepção, a participação de alunos e professores no processo de comunicação pode ser "interativa" (quando há a participação de mais de uma pessoa) e "não interativa" (quando somente um indivíduo está envolvido na ação comunicativa).

Os padrões de interações do discurso entre professores e alunos na sala de aula podem ser representados de duas maneiras: o triádico I-R-A (Iniciação - Resposta - Avaliação) 
e as interações não triádicas em cadeia, que podem ser identificadas quando o professor apresenta um feedback $(\mathrm{F})$ ou um prosseguimento $(\mathrm{P})$ à fala do aluno, com o objetivo de sustentar a sua produção discursiva e dar continuidade à interação: I-R-F-R-P-R... Essas cadeias podem ser abertas quando não apresentam uma avaliação ao seu final, ou fechadas, quando apresentam (MORTIMER; SCOTT, 2003). Os autores descrevem ainda cadeias em que uma pergunta do professor gera diferentes respostas por parte dos alunos e, por fim, interações geradas a partir de uma iniciação do estudante.

Mortimer e Scott (2003) acreditam que a ferramenta analítica do Quadro 8 constitui um importante instrumento para avaliar o discurso de sala de aula, porém podemos verificar que não tem o objetivo de caracterizar a estrutura da resposta do aluno, como é apresentado em Sasseron (2008); Bellucco e Carvalho (2014); Jiménez-Aleixandre et al. (2000) e a qualidade do argumento como indica Sampson e Blanchard (2012); Erduran et al. (2004) e Clark et al. (2007). Assim, para nós, este tipo de interação apresenta limitação em caracterizar-se como um "processo de construção social do argumento", pois não se sabe qual a estrutura da resposta do aluno e como ela foi construída, salvo a presença de um movimento discursivo quando se aprofunda a análise do papel do professor (Abordagem e Ações) e os aspectos de análise (Padrões de interação e Intervenções do professor).

No sentido de contribuir para a natureza social da argumentação científica e diante desta falta de clareza sobre os aspectos sociais para a produção da argumentação, existem autores que afirmam que os estudos etnográficos, por exemplo, teriam a capacidade de proporcionar uma melhor compreensão de como a argumentação científica é influenciada pela vida quotidiana dos alunos (BRICKER; BELL, 2008). Para outros, as análises sociológicas do discurso seriam outra opção para organizar um entendimento comum relativamente àquilo que está a acontecer na sala de aula e como os indivíduos devem comportar-se no espaço escolar ou fora dele (por exemplo, BERNSTEIN, 1993; BRICKER; BELL, 2008; BERLAND, 2011). Assim, qualquer programa educacional projetado para melhorar os processos de argumentação exigirá não apenas os elementos cognitivos do processo argumentativo (qualidade, estrutura e progressão), mas também irá requerer uma compreensão dos contextos sociais e culturais em que o argumento é realizado (DRIVER et al., 2000).

A análise e a síntese dos tópicos anteriores (estrutura, qualidade, processo e construção social do argumento) destinam-se a fornecer uma revisão e aprofundamento teórico para investigações futuras sobre a argumentação no ensino de Ciências. Neste sentido, não foi possível esclarecer nos modelos de estrutura e qualidade dos argumentos, no ensino de Ciências, citados anteriormente, as principais evidências que caracterizam, ou que estejam preocupados em analisar, as relações sociais dos sujeitos participantes na construção do argumento científico escolar. 


\section{II.3 Propondo dois instrumentos para análise do argumento}

A partir da nossa questão de pesquisa - Como se caracteriza o argumento de crianças e jovens em um contexto não formal de ensino de Ciências? -, à luz das premissas dos referenciais apresentados na seção anterior, emerge nosso objetivo em construir um instrumento metodológico para analisar o argumento de um grupo de crianças e jovens em um cenário de ensino não formal e apoiado por diferentes recursos de aprendizagem visando o desenvolvimento de atividades investigativas no ensino de Ciências. Organizamos a nossa proposição em dois instrumentos, o primeiro refere-se à estrutura do argumento e o segundo a qualidade do argumento e que estão apresentados a seguir.

\section{II.3.1 Os Elementos e Unidades Taxonômicas da Argumentação Científica}

As diversas pesquisas sobre os fundamentos essenciais da argumentação científica escolar (estrutura, qualidade, processo móvel e construção social), utilizadas neste trabalho, ofereceram-nos um conjunto de elementos e unidades - isto é, a relação das diferentes categorias evidenciadas no referencial apresentado - com os quais iremos trabalhar.

Nos tópicos anteriores, vimos que alguns trabalhos são orientadores para compreendermos principalmente a estrutura e a qualidade do argumento. A partir destas referências e de outras, detectamos um conjunto de elementos que integram a forma como o processo argumentativo no ensino de Ciências é estruturado e os reagrupamos num único quadro (Quadro 9). Primeiramente, organizamos os principais verbos passíveis de serem identificados no processo argumentativo em elementos designados Unidades Taxonômicas (UT). Percebemos que estas unidades têm origem em diferentes estudos e naqueles anteriormente citados (BELLUCCO; CARVALHO, 2014; JIMÉNEZ-ALEIXANDRE et al., 2000; SAMPSON; BLANCHARD, 2012; SAMPSON; CLARK, 2008; SASSERON, 2008).

Para facilitar o processo de análise do argumento científico em sala de aula, as UT são reagrupadas em componentes, sob a designação de Elementos Taxonômicos da Argumentação Científica (ETAC), que procuram caracterizar o argumento por meio de ações (orais e escritos) e que acontece durante a realização de atividades de investigação no ensino de Ciências (AIEC).

Quadro 9 - Elementos Taxonômicos da Argumentação Científica (ETAC).

\begin{tabular}{|c|c|c|}
\hline $\begin{array}{c}\text { Unidades taxionômi- } \\
\text { cas (UT) }\end{array}$ & ETAC & Definições \\
\hline $\begin{array}{c}\text { Responde e/ou Descre- } \\
\text { ve }\end{array}$ & $\begin{array}{c}\text { Elementos descritores de ideias/ } \\
\text { informações }\end{array}$ & $\begin{array}{c}\text { Respostas simples ou apoiadas por alega- } \\
\text { ções em busca de uma conclusão. Nor- } \\
\text { malmente surgem após uma pergunta }\end{array}$ \\
\hline $\begin{array}{c}\text { Explica } \\
\text { Justifica }\end{array}$ & $\begin{array}{c}\text { Elementos de sustentação de ideias/ } \\
\text { informações }\end{array}$ & $\begin{array}{c}\text { Sustenta uma alegação em busca de uma } \\
\text { conclusão }\end{array}$ \\
\hline $\begin{array}{c}\text { Organiza a informação } \\
\text { Classifica a informação }\end{array}$ & $\begin{array}{c}\text { Elementos organizadores de ideias/ } \\
\text { informações }\end{array}$ & $\begin{array}{c}\text { Lista de ideias e informações organizadas } \\
\text { ou classificadas que é utilizada para se }\end{array}$ \\
\hline
\end{tabular}




\begin{tabular}{|c|c|c|c|}
\hline $\begin{array}{c}\text { Unidades taxionômi- } \\
\text { cas (UT) }\end{array}$ & \multicolumn{2}{|c|}{ ETAC } & Definições \\
\hline & & & chegar a uma conclusão \\
\hline $\begin{array}{c}\text { Pergunta } \\
\text { Problematiza }\end{array}$ & \multicolumn{2}{|c|}{ Elementos de problematização } & $\begin{array}{l}\text { Perguntas simples ou elaboradas (proble- } \\
\text { máticas) para compreender o fenômeno } \\
\text { estudado ou introduzir novas ideias }\end{array}$ \\
\hline $\begin{array}{c}\text { Introduz ideias } \\
\text { Formula hipóteses } \\
\text { Prevê } \\
\text { Supõe } \\
\text { Avalia } \\
\text { Testa hipóteses } \\
\text { Induz } \\
\text { Deduz } \\
\text { Generaliza }\end{array}$ & \multicolumn{2}{|c|}{$\begin{array}{l}\text { Elementos de levantamento de hipó- } \\
\text { teses }\end{array}$} & $\begin{array}{c}\text { Suposições, avaliações, deduções, genera- } \\
\text { lizações ou previsões sobre conceitos, } \\
\text { fenômenos ou eventos passíveis de serem } \\
\text { colocados à prova }\end{array}$ \\
\hline $\begin{array}{c}\text { Define conceitos } \\
\text { Exemplifica } \\
\text { Relaciona } \\
\text { Reconhece } \\
\text { Retoma ideias (Revê) } \\
\text { Propõe } \\
\text { Delimita } \\
\text { Complementa } \\
\text { Sugere }\end{array}$ & \multirow{4}{*}{$\begin{array}{l}\text { Elementos cons- } \\
\text { trutores }\end{array}$} & De pensamento & $\begin{array}{l}\text { O pensamento é construído a partir de } \\
\text { definições, exemplos, relações, retomada } \\
\text { de ideias, complementações, sugestões }\end{array}$ \\
\hline $\begin{array}{l}\text { Raciocina (Lógica e } \\
\text { Proporcionalmente) }\end{array}$ & & De raciocínio & $\begin{array}{c}\text { O raciocínio pode ser apresentado de for- } \\
\text { ma lógica (a partir de elementos corretos) } \\
\text { ou proporcional (relacionando-o com as } \\
\text { variáveis) }\end{array}$ \\
\hline $\begin{array}{c}\text { Refuta } \\
\text { Critica } \\
\text { Questiona } \\
\text { Reivindica } \\
\text { Discorda }\end{array}$ & & $\begin{array}{l}\text { De oposição de } \\
\text { ideias }\end{array}$ & $\begin{array}{c}\text { A oposição de ideias é construída a partir } \\
\text { de questões, refutações, críticas, desacor- } \\
\text { dos e reinvindicações }\end{array}$ \\
\hline $\begin{array}{c}\text { Apoia } \\
\text { Defende ideias } \\
\text { Concorda } \\
\text { Confirma } \\
\text { Conclui } \\
\end{array}$ & & $\begin{array}{l}\text { De defesa e con- } \\
\text { clusão }\end{array}$ & $\begin{array}{l}\text { As ideias e informações podem ser apoia- } \\
\text { das, defendidas, confirmadas ou concluí- } \\
\text { das }\end{array}$ \\
\hline $\begin{array}{c}\text { Gosta } \\
\text { Não gosta } \\
\text { Exclama } \\
\text { Ri } \\
\text { Expressa sons }\end{array}$ & \multicolumn{2}{|c|}{ Elementos descritores de emoção } & $\begin{array}{c}\text { Não fazem parte de um argumento racio- } \\
\text { nal, mas expressa opiniões, sensações e } \\
\text { expressões sobre o fenômeno estudado ou } \\
\text { ideia defendida }\end{array}$ \\
\hline
\end{tabular}

Fonte: Elaborado pelos autores.

O Quadro 9 detalha as unidades e elementos da argumentação que julgamos ser recorrentes em aulas investigativas. Partimos da premissa de que a identificação destes elementos nos discursos dos alunos pode fornecer evidências sobre o processo de construção e de reconhecimento de significados e que podem ser justificados da seguinte maneira: 
a) Elementos descritores de ideias/informações: as unidades que caracterizam estes elementos, normalmente surgem após uma pergunta realizada pelo professor (por exemplo: "Professor - Qual a diferença entre sólido, líquido e gasoso?”). Trata-se de respostas simples ou apoiadas por alegações em busca de uma conclusão, mas não necessariamente respondem corretamente a pergunta inicial (ex.: "Aluno - O sólido é gelo, o líquido é água e gasoso é o ar que respiramos").

b) Elementos de sustentação de ideias/informações: estes elementos são caracterizados por unidades que buscam sustentar a alegação do professor ou de outros estudantes a fim de chegar a uma conclusão. Os estudantes tendem a explicar as alegações por meio de afirmações e/ou evidências empíricas. Segundo Clark e Sampson (2007), a sustentação de informações que são criadas pelos estudantes é colocada como discussão inicial. Grupos de alunos também podem apresentar afirmações opostas dentro de um episódio nas discussões estabelecidas (ex.: "Aluno - Todos os objetos permanecerão com diferentes temperaturas no mesmo ambiente").

c) Elementos organizadores de ideias/ informações: estes elementos são caracterizados por unidades que apresenta uma lista de ideias, pensamentos, informações organizadas e/ou classificadas para se chegar a uma conclusão. Ao relacionar estes elementos com os indicadores de Sasseron (2008), verifica-se uma relação com as ações desempenhadas nas tarefas de organizar, classificar e seriar os dados: (ex.: "Aluno - Eu peguei o gelo, levei para fora da sala, coloquei no sol e observei o que ia acontecer. O gelo derreteu, virou água e começou a sumir".)

d) Elementos de problematização: os estudantes expressam unidades que são caracterizadas por perguntas simples, elaboradas ou problematizadas para compreender o fenômeno estudado. Para Clark e Sampson (2007), as perguntas incluem comentários e feedbacks ou o posicionamento de outros grupos em face de uma determinada questão.

e) Elementos de levantamento de hipóteses: são formados por unidades que evidenciam suposições, avaliações, deduções, generalizações ou previsões sobre conceitos, fenômenos ou eventos passíveis de serem colocados à prova. Para Sasseron (2008), o levantamento de hipóteses aponta suposições acerca de certo tema e o teste de hipóteses concerne nas etapas em que se coloca à prova as suposições anteriormente levantadas. As unidades taxonômicas que representam este grupo também podem surgir sob a forma de uma suposição, caracterizada por uma afirmação ou uma pergunta (ex.: "Aluno - O gelo não seria a água congelada? Se eu pôr no sol ele não vai virar água?").

f) Elementos construtores: são formados por unidades que estão associadas ao processo de construção de significados e que podem ser de pensamento, de raciocínio (lógico ou proporcional), de oposição de ideias, defesa e conclusão. Os elementos construtores compreendem uma dimensão epistemológica, ou seja, a construção do pensamento se dá a partir de definições, exemplos, relações, retomada de ideias, complementação etc. Segundo Sasseron e Carvalho (2013), os elementos construtores de raciocínio são elementos que indicam a forma 
como o pensamento é exposto (raciocínio lógico) e como as variáveis se relacionam entre si (raciocínio proporcional) (ex.: "Professor - Qual a diferença do movimento das moléculas da água?" "Aluno - O gelo é devagar e a água é rápida."). Os elementos construtores de oposição de ideias incluem ataques aos fundamentos de uma afirmação ou diretamente à afirmação, ou seja, são caracterizados por unidades que especificam as condições em que a afirmação não será verdadeira. Por fim, os elementos construtores de defesa e conclusão são formados por unidades em que os participantes defendem afirmações e as suas ideias, além de serem também essenciais para o desenvolvimento de capacidades na defesa e conclusão dos seus argumentos.

g) Elementos descritores de emoção: trata-se de elementos em que os estudantes manifestam opiniões, sensações e expressões sobre o fenômeno estudado ou ideia defendida (ex.: "O que eu mais gostei foi ver a perna do besouro no microscópio"). Segundo Clark e Sampson (2007), ocasionalmente, os comentários de apelo emotivo não fazem parte da argumentação racional, sendo essencialmente emotivos no conteúdo, porém dão enfoque à veracidade e à autoridade.

Mesmo que os ETAC tenham origem em estudos sobre o 'argumento' e a 'argumentação' no ensino de Ciências, o seu uso está relacionado com a ampliação de diferentes referenciais, ou seja, podemos encontrar neste instrumento os Indicadores da Alfabetização Científica de Sasseron (2008) e as Características Campo-Dependentes de Bellucco e Carvalho (2014). Estes aspectos encontram-se ampliados para outros elementos, neste caso, a problematização, a oposição e a defesa de ideias e pensamento emotivo. $\mathrm{O}$ instrumento procura igualmente fornecer elementos para compreender as respostas (R) do aluno nos "Padrões de Interação" de Mortimer e Scott (2003), que não são especificados e complementam o "esquema básico de codificação hierárquica para classificar a estrutura argumentativa", de Clark e Sampson (2007).

\section{II.3.2 Níveis Hierárquicos da Qualidade do Argumento Modificado}

A partir dos trabalhos sobre a qualidade do argumento, apresentados anteriormente, sentimos a necessidade de levar em consideração a qualidade dos elementos de defesa e conclusão de ideias e não somente a qualidade da justificativa (SASSERON; CARVALHO, 2013) ou a qualidade da capacidade de refutação (ERDURAN et al., 2004). Assim, propomos uma reorganização do sistema hierárquico de categorias para avaliar a qualidade do argumento e denominamos de Níveis Hierárquicos da Qualidade do Argumento Modificado (Quadro 10). 
Quadro 10 - Níveis hierárquicos da qualidade do argumento modificado.

\begin{tabular}{|c|c|}
\hline Nível & Descrição \\
\hline 0 & Uma informação simples sem justificativa ou fundamento. \\
\hline 1 & $\begin{array}{c}\text { Uma ou mais informações com justificações ou fundamentos simples, mas sem conclusão e } \\
\text { refutação. }\end{array}$ \\
\hline 2 & $\begin{array}{c}\text { Uma ou mais informações com justificações ou fundamentos simples, com conclusão e sem } \\
\text { refutação. }\end{array}$ \\
\hline 3 & $\begin{array}{c}\text { Uma ou mais informações com justificações ou fundamentos simples, com conclusão e } \\
\text { refutação. }\end{array}$ \\
\hline 4 & $\begin{array}{c}\text { Uma ou mais informações com justificações ou fundamentos detalhados, mas sem conclu- } \\
\text { são e refutação. }\end{array}$ \\
\hline 5 & $\begin{array}{c}\text { Uma ou mais informações com justificações ou fundamentos detalhados, com conclusão e } \\
\text { sem refutação. }\end{array}$ \\
\hline 6 & $\begin{array}{c}\text { Uma ou mais informações com justificações ou fundamentos detalhados, com conclusão e } \\
\text { refutação. }\end{array}$ \\
\hline
\end{tabular}

Fonte: elaborado pelos autores.

Este quadro analítico, referente à qualidade do argumento, foi estruturado com o objetivo de hierarquizar o argumento com justificativas, conclusões e refutações, pois nem todos os turnos de falas que se analisam podem ser hierarquizados segundo os modelos anteriormente apresentados. Os argumentos mais simples consistem na introdução de ideias ou afirmações utilizadas para iniciar o processo de criação de diferentes níveis da qualidade do argumento. A evolução dos níveis discursivos dos alunos (do simples para o mais elaborado) começa a ser formado por argumentos acompanhados de afirmações que contenham dados ou garantias, contra afirmações, justificativas e refutações. Os argumentos com justificações ou fundamentos detalhados, com conclusão e refutação apresentam, no entanto, melhor qualidade do que aquelas que as não têm.

A partir dos instrumentos apresentados nos Quadros 9 e 10, esta pesquisa buscará caracterizar o argumento de um grupo de alunos durante o desenvolvimento de uma AIEC. Neste sentido, acreditamos que é possível compreender o argumento e argumentação, a partir da estrutura e da qualidade do argumento com os ETAC e os níveis modificados da qualidade do argumento.

\section{Metodologia}

\section{III.1 Sujeitos e Cenário da Pesquisa}

O desenvolvimento da nossa pesquisa aconteceu no contexto de uma oficina em ensino de Ciências dentro de um projeto de inclusão social, educacional e tecnológico designado por "Projeto Experimental de Educação Científica e Tecnológica (PEECT)". Este projeto de- 
senvolveu-se na região da Tapada das Mercês no concelho de Sintra em Portugal. O Projeto EECT atende alunos de várias escolas da região, alguns do primeiro ciclo (anos iniciais do ensino fundamental), mas principalmente do segundo e terceiro ciclos (ensino fundamental e médio respectivamente). Este projeto recebe apoio e financiamento do "Programa Escolhas"3, programa governamental que também apoia outros projetos em todo território português.

O Projeto EECT se desenvolve num contexto social vulnerável, onde predominam famílias maioritariamente de imigrantes. Para apoiar os alunos oriundos desta realidade, o projeto procura desenvolver ações de "inclusão escolar", "educação não formal" e "inclusão digital" durante todo o ano num espaço que possui Tecnologias de Informação e Comunicação para o Ensino (TICE) e desenvolve diversas oficinas de formação. As principais oficinas são de aeromodelismo, nas quais os participantes constroem aeromodelos e modelos de foguetes (temática relacionada com o espaço, o universo, a aeronáutica e a astronomia), além de atividades com a robótica (temática associada às energias alternativas), em que se constroem modelos de barcos e carros, movidos a energia solar, e turbinas eólicas.

Inseridas num contexto não formal, estas atividades visam complementar o ensino formal de educação científica e tecnológica que é ministrado nas escolas da região de Sintra em Portugal, possuindo uma componente mais prática do que meramente expositiva (teórica).

A nossa amostra foi formada por 13 crianças e jovens participantes do projeto EECT, com idade de 12 a 14 anos, convidadas pela equipe a participar de uma Oficina de Ensino de Ciências que durou uma semana. Os participantes entregaram aos coordenadores do projeto EECT uma ficha de autorização dos pais para participar das atividades que seriam filmadas. Os participantes foram identificados respetivamente pelos códigos A1, A2 etc., de forma a preservar a sua identidade.

Para o desenvolvimento da investigação, contamos ainda com o apoio da equipe do projeto EECT, formada pelo coordenador (professor especialista em ciência e tecnologia com 20 anos de experiência à docência), uma psicóloga, um técnico de informática e uma estagiária. A equipe ajudou na elaboração das atividades e ofereceu apoio aos participantes durante o desenvolvimento da oficina.

\section{III.2 Os Episódios em forma de Hipermídia}

A oficina temática, desenvolvida no âmbito do projeto EECT, teve como tema o estudo do voo de foguetes, satélites e aviões, com o objetivo de aprofundar os conceitos científicos da "Oficina de Aeromodelos", que os participantes já desenvolviam no projeto EECT.

\footnotetext{
${ }^{3}$ O Programa Escolhas é financiado pelo Instituto da Segurança Social, pela Direção Geral de Educação de Portugal e pelo Fundo Social Europeu, através do Programa Operacional Potencial Humano - POPH/QREN. Este Programa financia projetos de inclusão social em comunidades vulneráveis, muitos dos quais localizados em territórios onde se concentram descendentes de imigrantes e minorias étnicas em todo o território Português (Disponível em: <http://www.programaescolhas.pt/>).
} 
Foi elaborado, para o desenvolvimento deste trabalho, um recurso digital temático designado por Módulo Temático Virtual (MTV) (FERNANDES; RODIGUES; FERREIRA, 2015). O MTV elaborado procurou apresentar atividades que fizessem sentido aos participantes e abrangessem conceitos físicos e com o objetivo de estimular o diálogo e a troca de informações. O conteúdo que seria desenvolvido com os participantes ficou estruturado em três episódios:

Episódio 1: Conhecendo o Ar e a Atmosfera;

Episódio 2: Conhecendo o movimento dos satélites;

Episódio 3: Conhecendo o voo do Avião.

Cada episódio continha entre duas a três atividades ${ }^{4}$ baseadas no Ensino de Ciências por Investigação (ENCI). Todos os estudantes tinham acesso a um computador e os episódios, com suas atividades, foram planejados levando em consideração os elementos e etapas das Atividades Investigativas em Ensino de Ciências (AIEC) de Fernandes et al. (2015).

Quadro 11 - Principais elementos e etapas de investigação.

\begin{tabular}{|c|c|c|}
\hline $\mathbf{N}^{\mathbf{0}}$ & Elementos das AIEC & Etapas de Investigação \\
\hline 1 & Problema & $\begin{array}{c}\text { Explorar o mundo } \\
\text { Apresentar um problema } \\
\text { Refletir sobre o problema }\end{array}$ \\
\hline 2 & Hipótese & $\begin{array}{c}\text { Gerar hipóteses } \\
\text { Avaliar as hipóteses }\end{array}$ \\
\hline 3 & Processo investigativo & $\begin{array}{c}\text { Planear a investigação } \\
\text { Investigar }\end{array}$ \\
\hline 4 & Interpretação & $\begin{array}{c}\text { Analisar os dados obtidos } \\
\text { Interpretar as novas informações }\end{array}$ \\
\hline 5 & Conclusão & $\begin{array}{c}\text { Sistematizar e registrar } \\
\text { Comunicar as informações } \\
\text { Aplicar o conhecimento a novas situações }\end{array}$ \\
\hline
\end{tabular}

Fonte: Fernandes et al. (2015, modificado).

Foram levadas em consideração três etapas ou partes: 1) apresentação de um problema e descrição das respetivas hipóteses; 2) a interação com Objetos Virtuais de Aprendizagem (OVA), acompanhada de um pequeno roteiro (processo investigativo); e 3) a explicação oral daquilo que foi observado durante a interação (interpretação e conclusão). Ou seja, para que fossem consideradas Atividades de Investigação (AI), as atividades teriam que apresentar uma situação-problema que levasse ao levantamento de hipóteses. A interação com o objeto informático iria favorecer as respostas para as situações questionadas. Por outro lado, os registros escritos, juntamente com a argumentação dos participantes, forneceriam o feedback sobre

\footnotetext{
${ }^{4}$ No Episódio I foram desenvolvidas três atividades, no Episódio II foram três atividades e no Episódio III foram duas atividades.
} 
o processo de aprendizagem. No final de cada episódio, buscou-se recuperar o tema e os principais conceitos estudados através da argumentação das crianças e jovens participantes.

$\mathrm{Na}$ apresentação dos resultados iremos aprofundar somente a análise dos dados do Episódio III, que apresenta os principais elementos necessários para que um avião possa voar (Quadro 12).

Quadro 12 - Quadro sintético do Episódio III e atividades (AT) do MTV.

\begin{tabular}{|c|c|c|c|}
\hline \multicolumn{4}{|c|}{ EPISÓDIO III - CONHECENDO O VOO DO AVIÃO } \\
\hline & Atividade & Objetivo & Descrição \\
\hline 1 & De onde vem o avião? & $\begin{array}{l}\text { Apresentar os pri- } \\
\text { meiros conceitos } \\
\text { sobre o voo do avi- } \\
\text { ão através de um } \\
\text { vídeo. }\end{array}$ & $\begin{array}{l}\text { Fazer o levantamento inicial do conhecimento } \\
\text { quotidiano dos alunos sobre o voo do avião. O } \\
\text { vídeo apresentado está acompanhado de um } \\
\text { texto, sendo que a atividade consiste em identi- } \\
\text { ficar no texto os conceitos desconhecidos e pro- } \\
\text { porcionar a aprendizagem de novos conceitos. }\end{array}$ \\
\hline 2 & O que faz o avião voar? & $\begin{array}{l}\text { Caracterizar os } \\
\text { princípios básicos } \\
\text { para o voo do avião. }\end{array}$ & $\begin{array}{l}\text { Através de uma simulação e de um vídeo, os } \\
\text { alunos descobrem os princípios básicos para o } \\
\text { voo do avião. }\end{array}$ \\
\hline
\end{tabular}

\section{III.3 Eixos de análise}

Com o objetivo de compreender o desempenho dos alunos-participantes por meio dos Elementos Taxonômicos da Alfabetização Científica (ETAC) e dos níveis de Qualidade do Argumento Modificado, analisaremos o Episódio III por meio das etapas das Atividades Investigativas do Ensino de Ciências (AIEC) de Fernandes et al. (2015).

Etapa 1: Problemas e hipóteses - explorar o mundo e gerar hipóteses.

Etapa 2: Processo de investigação - construir a compreensão do processo.

Etapa 3: Interpretação - analisar os dados.

Etapa 4: Conclusão - comunicar as informações e aplicar o conhecimento em novas situações.

\section{Resultados}

\section{Etapa 1: Problemas e hipóteses - explorar o mundo e gerar hipóteses}

Esta primeira etapa tem início com o processo de problematização e levantamento de hipóteses através da apresentação de um vídeo que explora os conceitos que caracteriza o "Voo dos aviões". Os diálogos dos participantes foram organizados em turnos de fala (T) e a análise destes turnos será apresentada em forma de Unidades Taxonômicas (UT) e Qualidade 
do Argumento Modificado (QAM). A apresentação do problema deste Episódio foi conduzida oralmente, tendo-se seguido pelo levantamento de hipóteses dos participantes.

Quadro 13 - Turnos de fala que caracterizam as UT e QAM para a Etapa 1.

\begin{tabular}{|c|l|l|c|}
\hline T & \multicolumn{1}{|c|}{ Diálogos } & ANÁLISE/ UT & QAM \\
\hline 8 & $\begin{array}{l}\text { Mediador: Então, antes de vermos o site ou qualquer outra } \\
\text { coisa, o que é que vocês acham que faz o avião voar? }\end{array}$ & $\begin{array}{l}\text { Formula hipótese } \\
\text { Defende ideia }\end{array}$ & 0 \\
\hline 9 & A3: o motor! & $\begin{array}{l}\text { Complementa } \\
\text { Formula hipótese }\end{array}$ & 0 \\
\hline 10 & Mediador: ele disse que é o motor. Mais alguma outra coisa? & Complementa \\
\hline 11 & A5: o vento. & $\begin{array}{l}\text { Organiza infor- } \\
\text { mação } \\
\text { Formula hipótese } \\
\text { Conclui }\end{array}$ & 0 \\
\hline 12 & Mediador: o vento... O que mais? & Participantes: o motor, o condutor, o vento... & \\
\hline
\end{tabular}

Com as informações disponibilizadas pela sequência de diálogos, percebemos a construção de hipóteses pelos participantes para o problema conduzido pelo mediador. Destacamos que os argumentos dos participantes são bastante lógicos, embora ainda pouco consistentes e frágeis. Segundo Fernandes et al. (2015), para que os alunos consigam gerar as suas hipóteses é importante que o professor deixe claro aos alunos que eles devem fazer suas predições para as questões-foco, antes de iniciar o processo de investigação. Para avaliar as hipóteses dos alunos, sugere-se que o professor/mediador recolha os resultados conhecidos pelos alunos e tente listá-los para que estes sejam orientadores do processo de investigação (FERNANDES et al., 2015). De qualquer modo, o argumento anterior reflete o início da construção das relações de causa e efeito para a situação investigada.

A qualidade do argumento tem o Nível 0, uma vez que são informações simples, sem justificativa ou fundamento.

\section{Etapa 2: Processo de investigação - construir a compreensão do processo}

Esta etapa consistia na identificação dos conceitos presentes no vídeo pelos aprendizes e nos quais eles apresentavam dúvidas. Para isso, pedimos aos estudantes que destacassem de alguma forma (sublinhando, por exemplo) as palavras no texto impresso da narração do vídeo. Em seguida, pedimos-lhes que escrevessem as palavras que desconheciam, ou nas quais tinham dúvidas, numa ficha online para que a equipe e o professor pudessem trabalhar com eles. À medida que os alunos iam escrevendo, as palavras apareciam no computador da equipe: turbinas, pressão, Santos Dumont, Horizonte, etc. Após a identificação das palavras o professor iniciou algumas explicações: 
Quadro 14 - Turnos de fala que caracterizam as UT e QAM para a Etapa 2.

\begin{tabular}{|c|c|c|c|}
\hline T & Falas & Análise/ UT & QAM \\
\hline 42 & $\begin{array}{c}\text { Professor: vejam pessoal, as asas empurram o ar para } \\
\text { baixo, e o ar? O que é que o ar faz com as asas do avião? }\end{array}$ & & \\
\hline 43 & A3: [empurra-as] Para cima. & $\begin{array}{c}\text { Explica } \\
\text { Raciocina de forma } \\
\text { proporcional } \\
\text { Relaciona }\end{array}$ & 1 \\
\hline 44 & A5: Empurra para cima. & $\begin{array}{c}\text { Explica } \\
\text { Confirma } \\
\text { Raciocina de forma } \\
\text { proporcional } \\
\text { Relaciona }\end{array}$ & 2 \\
\hline 45 & $\begin{array}{c}\text { Professor: Empurra o avião para cima. Se o ar empurra o } \\
\text { avião para cima, ele cai? }\end{array}$ & $\begin{array}{c}\text { Discorda } \\
\text { Justifica }\end{array}$ & 3 \\
\hline & A3: Não, [porque o ar] empurra para cima. & $\begin{array}{c}\text { Raciónio lógico } \\
\text { Conclui }\end{array}$ & \\
\hline
\end{tabular}

No turno 43, a qualidade do argumento do aprendiz A5 inicia-se com o Nível 1 e no turno 46 podemos verificar o Nível 3: "[o avião] não cai, [por que o ar] empurra [a asa do avião] para cima", ou seja, é uma afirmação simples com justificativa (por que o ar empurra a asa do avião para cima), refutação (não cai) e conclusão (não, empurra para cima).

Verifica-se também nesta etapa que houve uma evolução dos argumentos, que se revelaram mais consistentes e menos frágeis em comparação com a Etapa 1. No turno 43, o participante A3 explica sua ideia (elemento de sustentação de ideias), raciocina de forma proporcional (elemento construtor de raciocício) e faz relação com a situação-problema (elemento construtor de pensamento): "[o ar empurra as asas do avião] Para cima.". No turno 45 o professor, apresenta outra situação problema: "Se o ar empurra o avião para cima, ele cai? (Professor)", e o participante A3 discorda do professor (elemento de oposição de ideias), justifica a sua discordânica (elemento de sustentação de ideias), realiza um raciocício lógico (elemento construtor de raciocínio) e conclui a sua afirmação (elemento de defesa e conclusão): "Não [cai], [porque o ar] empurra [o avião] para cima (A3)". Construções deste tipo caracterizar-se-ão ao longo da atividade e são reforçadas principalmente durante as fases de investigação, interpretação e conclusão.

Também percebemos que a atividade de investigação contribuiu para que os aprendizes justificassem corretamente o conceito, mas em cooperação com outro participante (disposição sócio afetivas), como exemplificamos a seguir: 
Quadro 15 - Turnos de fala que caracterizam as UT e QAM para a Etapa 2.

\begin{tabular}{|c|c|c|c|}
\hline T & Diálogos & Análise/ UT & QAM \\
\hline 49 & $\begin{array}{c}\text { Professor: Os motores são as turbinas. Qual é a função das tur- } \\
\text { binas? }\end{array}$ & \\
\hline 50 & A6: o motor empurra o avião para a frente. & $\begin{array}{c}\text { Explica } \\
\text { Raciocínio lógico } \\
\text { Relaciona }\end{array}$ & 1 \\
\hline 51 & Professor: empurrar o avião para a frente. & & 1 \\
\hline 52 & A3: e ele vai para a frente. & $\begin{array}{c}\text { Explica } \\
\text { Raciocínio lógico } \\
\text { Complementa }\end{array}$ & 1 \\
\hline
\end{tabular}

Podemos verificar nos turnos 50 e 52 que a cooperação com outros estudantes se caracterizou pelo complemento de ideias entre os aprendizes A6 e A3: "o motor empurra o avião para a frente (A6) e ele vai para a frente (A3)". Assim, os dois participantes recorreram aos ETAC de sustentação de ideias, construção de raciocínio lógico e de pensamento. Neste sentido, podemos perceber que ocorreu também um movimento e progressão do argumento (BERLAND; REISER, 2011; DRIVER et al., 2000; BERLAND; MCNEILL, 2010), ou seja, segundo Berland e Reiser (2001, p. 199) os participantes "constroem afirmações e defendem as suas próprias afirmações e as de terceiros".

\section{Etapa 3: Interpretação - analisar os dados}

Nesta etapa, procuramos analisar a forma como decorreu o processo de interpretação das atividades após as etapas de problematização, levantamento de hipóteses e processo investigativo. O professor/coordenador do projeto também participou das discussões, procurando relacionar as atividades do MTV com as atividades do projeto EECT sobre o "Voo dos Aviões". Nesta etapa, o professor buscou discutir com os estudantes a "função das asas e do motor do avião". Nos diálogos que se seguem entre A3, A5 e o professor, pode-se observar que se trata de uma recuperação dos principais conceitos identificados na etapa de problematização e levantamento de hipóteses.

Quadro 16 - Turnos de fala que caracterizam as UT e QAM para a Etapa 3.

\begin{tabular}{|c|c|c|c|}
\hline $\mathbf{T}$ & Diálogos & Análise/ UT & QAM \\
\hline 85 & $\begin{array}{c}\text { Professor: Tenho aqui um modelinho de avião que vocês } \\
\text { já viram. A pergunta é: qual é a função da asa de um } \\
\text { avião? }\end{array}$ & & \\
\hline 86 & A3: empurra o vento para baixo. & $\begin{array}{c}\text { Explica } \\
\text { Raciocina de forma } \\
\text { lógica } \\
\text { Retoma ideias (revê) } \\
\text { Conclui }\end{array}$ & 2 \\
& & & \\
\hline
\end{tabular}




\begin{tabular}{|c|c|c|c|}
\hline 87 & $\begin{array}{c}\text { Professor: Se a asa empurra o vento para baixo o que é } \\
\text { que o vento faz? }\end{array}$ & \\
\hline 88 & A5: empurra o avião para cima. & $\begin{array}{c}\text { Explica } \\
\text { Raciocina de forma } \\
\text { proporcional } \\
\text { Conclui }\end{array}$ & 2 \\
\hline 89 & A3: empurra para cima. & $\begin{array}{c}\text { Retoma ideias (revê) } \\
\text { Explica } \\
\text { Raciocina proporcional } \\
\text { Confirma } \\
\text { Conclui }\end{array}$ & 2 \\
\hline 90 & $\begin{array}{c}\text { Professor: Empurra o avião para cima e ele consegue ir, } \\
\text { tudo bem? }\end{array}$ & \\
\hline
\end{tabular}

Nos turnos de fala do Quadro 16, inicialmente, os participantes comentam sobre a "lei da ação e reação" sem saber de fato que existe a $3^{\text {a }}$ Lei de Newton, mas que é caracterizada nas suas falas. O estudante A3 retoma a ideia e fornece uma explicação para a pergunta do professor, que passa por um raciocínio lógico e proporcional (SASSERON; CARVALHO, 2009, 2013; BELLUCO; CARVALHO, 2014): "Se a asa de um avião empurra o vento para baixo, [logo] o vento empurra o avião para cima".

A conclusão a que chegamos com esta alegação é a de que a atividade investigativa e os recursos midiáticos ajudaram os alunos a compreender que "a função da asa do avião é empurrar o vento para baixo para que o vento empurre o avião para cima". Esta análise mostra que A3 utilizou cinco Unidades Taxonômicas na sua fala: a recuperação de ideias; a explicação de uma questão; o raciocínio lógico e proporcional demonstrado na estruturação coerente dos seus argumentos; a confirmação e a conclusão coerente das suas ideias. Ou seja, apoiou-se em elementos de sustentação de ideias (explicações) e organizou os seus argumentos sobre elementos de construção (de pensamento, raciocínio e conclusão).

Quadro 17 - Turnos de fala que caracterizam as UT e QAM para a Etapa 3.

\begin{tabular}{|c|c|c|c|}
\hline T & Diálogos & Análise/ UT & QAM \\
\hline 90 & $\begin{array}{c}\text { Professor: Empurra o avião para cima e ele conse- } \\
\text { gue ir, tudo bem? }\end{array}$ & $\begin{array}{c}\text { Introduz a ideia } \\
\text { Raciocina de forma } \\
\text { lógica } \\
\text { Complementa }\end{array}$ & 1 \\
\hline 91 & A3: E o motor faz ele [o avião] ir para frente. & $\begin{array}{c}\text { Professor: E o motor, que fica em baixo, faz ele ir } \\
\text { para frente. }\end{array}$ & \\
\hline
\end{tabular}

No turno 91, A3 introduz outra ideia e complementa os argumentos anteriores: “... e o motor faz [o avião] ir para frente”. É apresentado um elemento de construção de 
pensamento (SAMPSON; CLARK, 2006) e ao mesmo tempo um elemento de levantamento de hipóteses.

Assim, as ideias de A3, a partir dos turnos 86 a 91, são: “As asas do avião empurram o vento para baixo, o vento empurra o avião para cima e o motor o faz ir para frente". E deste modo, A3 produziu um texto oral justificando a alegação do professor.

\section{Etapa 4: Conclusão - comunicar as informações e aplicar o conhecimento em novas si- tuações}

Na última etapa, os participantes conseguem aprofundar o argumento e aplicar o conhecimento sobre a função do motor do avião em novas situações:

Quadro 18 - Turnos de fala que caracterizam as UT e QAM para a Etapa 4.

\begin{tabular}{|c|c|c|c|}
\hline $\mathbf{T}$ & Diálogos & Análise/ UT & QAM \\
\hline 123 & $\begin{array}{l}\text { Professor: e se eu tiver um avião grande? Viajar com } \\
\text { pessoas... }\end{array}$ & & \\
\hline 124 & A6: tem que ter o motor. & $\begin{array}{c}\text { Explica } \\
\text { Formula hipótese } \\
\text { Raciocina de forma lógica } \\
\text { Relaciona } \\
\text { Complementa } \\
\end{array}$ & 1 \\
\hline 125 & Professor. E qual é a função do motor? & & \\
\hline 126 & A6: É para ele [o avião] andar e tentar levantar voo. & $\begin{array}{c}\text { Justifica } \\
\text { Raciocina de forma lógica } \\
\text { Classifica a informação }\end{array}$ & 5 \\
\hline
\end{tabular}

Podemos verificar nos turnos 124 e 126 que A6 recorre aos elementos de organização de ideias, isto é, que a função do motor "é para ele andar e tentar levantar voo". Neste sentido, podemos perceber que A6 apresenta informações com justificativas ou fundamentos detalhados com conclusão, porém sem nenhuma refutação. Estes turnos também são caracterizados por ETAC de levantamento de hipóteses e construção do pensamento (para viajar com as pessoas tem que ter motor), sustentação de ideias e raciocínio lógico (tem que ter motor para o avião andar e tentar levantar voo).

Em busca de uma compreensão mais aprofundada do episódio que acabamos de analisar (Episódio III), comparamos os argumentos da segunda atividade do primeiro episódio (EPI - AT 2) com as duas últimas atividades do Episódio III (Fig. 4). 


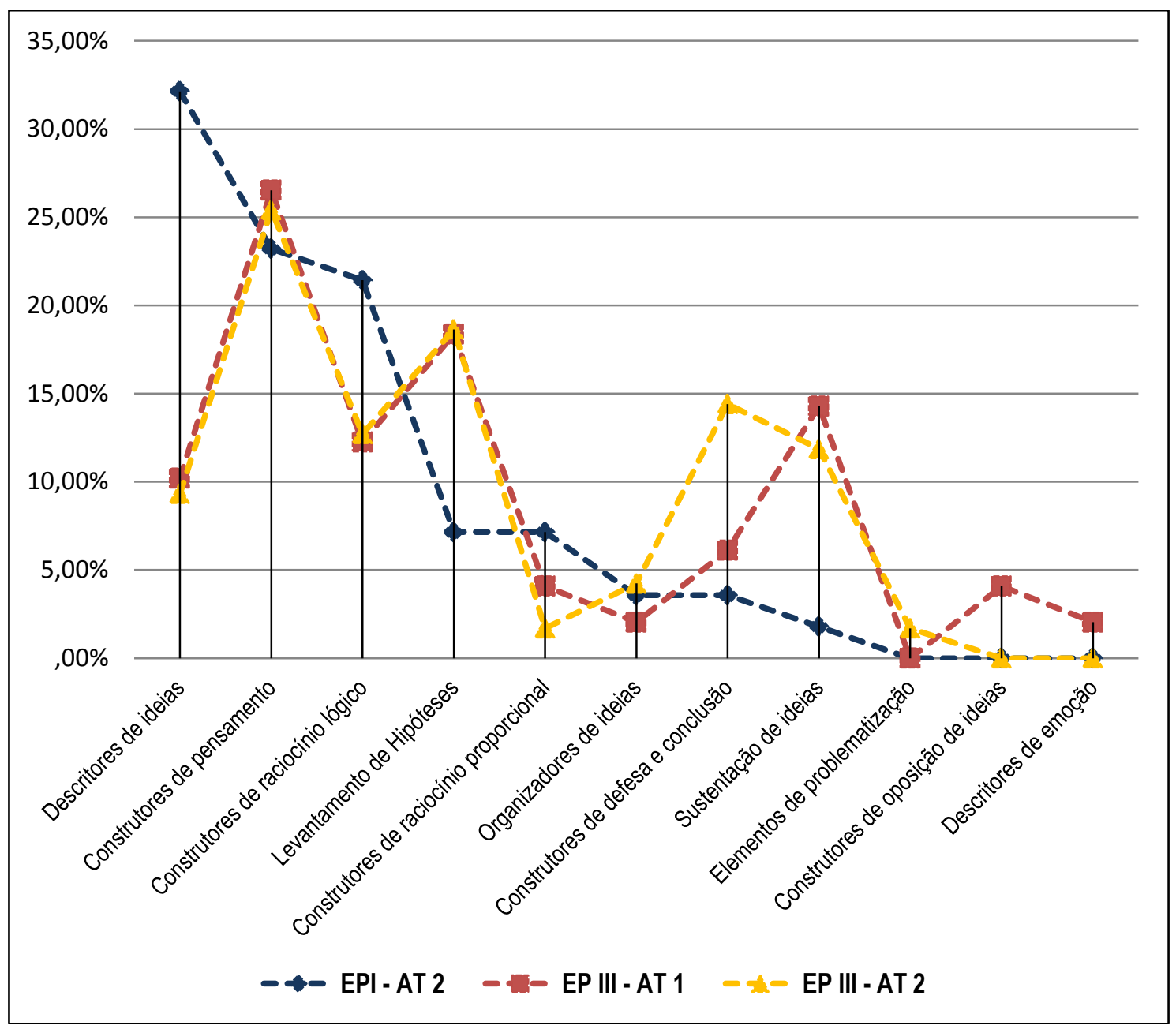

Fig. 4 - Comparação dos ETAC do Episódio I com o Episódio III.

Na Fig. 4, podemos verificar que o Episódio I (Conhecendo o ar e atmosfera) possui uma maior percentagem de elementos descritores de ideias e informações em comparação com o Episódio III. Ou seja, no primeiro episódio, os participantes apresentaram respostas simples após a apresentação de uma pergunta. Eram respostas diretas com poucos elementos de sustentação de ideias ( $2 \%$ ), enquanto no último episódio os aprendizes apresentaram menos descritores de ideias (10.0\%) e mais elementos construtores de defesa e sustentação de ideias (aproximadamente 15.0\%). Estes dados indicam que nos três episódios se verifica a presença de reconhecimento do contexto e os participantes conseguiram selecionar significados, mas somente a partir do Episódio III (Conhecendo o voo dos aviões) que os participantes conseguiram produzir textos orais justificando corretamente o conceito.

Estes resultados podem estar essencialmente relacionados com as atividades de investigação desenvolvidas, com o trabalho colaborativo verificado entre os participantes, com 
o apoio da equipe do Projeto, no sentido de esclarecer as dúvidas e com a reestruturação de pensamentos e ideias por via do debate argumentativo (sustentação de ideias).

Por outro lado, a análise do argumento dos participantes no Episódio I apresentou uma percentagem significativa de elementos construtores de raciocínio lógico (aproximadamente 22.0\%), em comparação com o Episódio III (aproximadamente 13.0\%). Esta diferença relacionar-se-ia com o grau de dificuldade constatado entre os dois episódios, ou seja, enquanto no primeiro episódio pretendíamos introduzir a temática e desenvolver atividades lúdicas para identificar e trabalhar alguns conceitos (Episódio I), no último procurávamos aprofundar os conceitos mais elaborados de forma a cumprir o objetivo da pesquisa (Episódio III). Uma vez que as atividades do último episódio eram mais elaboradas, foi possível identificar uma percentagem significativa dos elementos de levantamento de hipóteses (aproximadamente 19.0\%) em comparação com o primeiro episódio.

Os elementos taxonômicos que obtiveram uma baixa percentagem em todos os Episódios relacionavam-se com os elementos construtores do raciocínio proporcional, com a problematização, com os descritores de emoções, com os organizadores e oposição de ideias (ver Figura 4). Estes dados permitem inferir que, após a identificação de que tais habilidades não estão a ser caracterizadas, é importante que o professor ou o mediador do processo de ensinoaprendizagem crie sequências de ensino, módulos temáticos, ações ou estimule argumentos capazes de desenvolver tais capacidades de pensamento científico.

Chamamos igualmente a atenção para o fato que se verificou uma evolução ao nível da estrutura da argumentação através da análise dos ETAC entre o Episódio I e o Episódio III.

\section{Conclusão}

A investigação empírica e teórica sobre o 'argumento' e a 'argumentação' na educação científica tornou-se, nas últimas décadas, um dos referenciais mais importantes para a compreensão da construção do pensamento das crianças e dos jovens durante o desenvolvimento de atividades investigativas (DRIVER et al., 2000; ERDURAN et al., 2004; SAMPSON; CLARK, 2008; SAMPSON; CLARK, 2006; SASSERON; CARVALHO, 2013; JIMÉNEZ-ALEIXANDRE; PUIG, 2012).

Os instrumentos apresentados na revisão da literatura deste estudo podem fornecer um conjunto de informações sobre os elementos essenciais de como os alunos geram discussões no contexto da educação científica, ou seja, como saber se o argumento desenvolvido durante a realização de uma AIEC atinge os objetivos desejados? Como saber se o pensamento dos alunos está a ser desenvolvido durante uma AIEC? Para nós, a resposta para tais questões depende da estrutura, da qualidade, do movimento e dos aspectos sociais do argumento escolhidos para a análise.

Existem diferentes instrumentos que buscam categorizar a estrutura e qualidade do argumento e que são instrumentos de análise muito próximos. Por exemplo, os quadros de- 
senvolvidos por Bellucco e Carvalho (2014), Sasseron (2008), Sasseron e Carvalho (2013) assemelham-se no que se refere à seriação, classificação e organização de informações, bem como à justificativa, à explicação, à previsão e ao raciocínio lógico e proporcional da argumentação. O papel do professor é evidenciado em Sasseron e Carvalho (2013) e Mortimer e Scott (2003) quando estes autores evidenciam as ações e o propósito do professor, mesmo tendo referências teóricas diferentes para as suas proposições. Além disso, não está claro nos trabalhos apresentados o real significado da influência do contexto social para a produção do argumento. Ou seja, os aspectos sociais que contribuem para a construção da argumentação são somente aqueles construídos na sala de aula através de ações colaborativas (numa perspectiva sociocultural) ou são aqueles que acontecem fora da escola, construídos no contexto das relações familiares, econômicas e políticas? Uma sugestão seria levar em consideração os estudos etnográficos ou sociológicos do discurso e as suas relações com a alfabetização científica.

À luz destes pressupostos, buscamos analisar o argumento de um grupo de crianças e jovens em um cenário de ensino não formal e apoiado por diferentes recursos de aprendizagem visando o desenvolvimento de atividades investigativas no ensino de ciências (AIEC). Neste sentido, buscamos responder a seguinte questão: Como se caracteriza o argumento de crianças e jovens em um contexto não formal de ensino de Ciências?

Para responder a tal questão, foi elaborado um instrumento de análise do argumento por meio de uma taxonomia (ou unidades taxonômicas - UT) e que teve como objetivo organizar as estruturas do argumento de diferentes estudos para o planejamento, execução e comunicação dos resultados de investigações sobre o argumento e a argumentação no ensino de Ciências, facilitando ainda a compreensão do processo de construção do pensamento científico. As UT básicas e os ETAC da estrutura do argumento, exemplificado nas atividades desenvolvidas num projeto de educação científica e tecnológica, sugerem uma série de mensagens fundamentais sobre a natureza da argumentação no ensino de Ciências. Em primeiro lugar, as UT vêm auxiliar o professor a identificar os elementos que estruturam a argumentação desenvolvida durante uma AIEC. Em segundo lugar, estas unidades, organizadas em ETAC (Quadro 9), podem movimentar-se ao longo de uma atividade, demonstrando quais elementos são mais característicos.

Uma conclusão importante deste trabalho diz respeito ao fato de as categorias evidenciadas nos Quadros 9 e 10 não poderem ser pensadas como unidades isoladas e autônomas, mas sim num continuum de evolução, caracterizando-se em movimentos discursivos, ou seja, elementos argumentativos, do mais simples ao mais complexo (BERLAND; MCNEILL, 2010; BERLAND; REISER, 2011).

Também foi evidenciado que a qualidade do argumento cresceu ao longo das discussões, uma vez que novos elementos foram apresentados e incorporados na argumentação, conferindo-lhe mais coesão (SASSERON; CARVALHO, 2009, 2013). 
Estando na posse dos Elementos das Atividades de Investigação de Ensino de Ciências (problema, hipótese, processo de investigação, interpretação e conclusão) (Quadro 11), percebemos que existe uma aproximação com o nosso instrumento de análise que merece ser aprofundado em outras investigações e está caracterizado no Quadro 19.

Quadro 19 - Relação entre os Elementos das AIEC e os ETAC.

\begin{tabular}{|c|c|c|c|}
\hline $\mathbf{N}^{\mathbf{0}}$ & $\begin{array}{c}\text { ELEMENTOS DAS } \\
\text { AIEC }\end{array}$ & \multicolumn{2}{|c|}{ ETAC } \\
\hline 1 & Problema & Elementos de problematização & \\
\hline 2 & Hipótese & Elementos de formulação de hipóteses & \\
\hline 3 & Processo de investigação & $\begin{array}{r}\text { Elementos de sustentação de ideias/ } \\
\text { informações } \\
\text { Elementos organizadores de ideias/ } \\
\text { informações }\end{array}$ & \multirow{2}{*}{$\begin{array}{c}\text { Elementos descritores } \\
\text { de ideias/ informações } \\
\text { Elementos descritores } \\
\text { de emoções }\end{array}$} \\
\cline { 1 - 2 } & Interpretação & $\begin{array}{c}\text { Elementos construtores de pensamento } \\
\text { Elementos construtores de raciocínio } \\
\text { Elementos construtores de oposição de } \\
\text { ideias }\end{array}$ & \\
\hline 5 & Conclusão & Elementos de defesa e conclusão & \\
\hline
\end{tabular}

De acordo com o Quadro 19, os elementos descritores de ideias/informações e emoções são característicos de todos os elementos das AIEC, o que significa que podem estar presentes em qualquer etapa.

Um dos limites deste estudo reside na ausência de ações e do papel do professor no desenvolvimento do argumento, destacando somente os instrumentos ETAC (Quadro 9) e os níveis hierárquicos da Qualidade do Argumento Modificado (Quadro 10). Outra limitação reside no número de estudos, aqui apresentados, que incidem sobre 'argumento' e 'argumentação', uma vez que tal temática é amplamente discutida na educação científica. Estudos futuros podem centrar-se num tópico da revisão especial e expandir a investigação através de bases de dados e revistas da área sob a forma de revisão sistemática e apontar limites, possibilidades e complementar o sistema de categorização apresentado nos Quadros 9 e 10.

\section{Agradecimentos}

Os autores gostariam de agradecer às crianças do "Projeto Experimental de Educação Científica e Tecnológica (PEECT)” do Programa Escolhas em Portugal, aos revisores anônimos pelas cuidadosas observações que fizeram às versões anteriores do manuscrito e à "Fundação para a Ciência e a Tecnologia - FCT" pelo financiamento do projeto. 


\section{Referências}

FERNANDES, G.; RODRIGUES, A.; FERREIRA, C. Módulos temáticos virtuais: uma proposta pedagógica para o ensino de ciências e o uso das TICs. Caderno Brasileiro de Ensino de Física, Florianópolis, v. 32, n. 3, p. 934-962, out. 2015. Disponível em: <https://periodicos.ufsc.br/index.php/fisica/article/view/2175-7941.2015v32n3p934>.

BELLUCCO, A.; CARVALHO, A. M. P. de. Uma proposta de sequência de ensino investigativa sobre quantidade de movimento, sua conservação e as leis de Newton. Caderno Brasileiro de Ensino de Física, v. 31, n. 1, p. 30-59, 2014. https://doi.org/10.5007/21757941.2014v31n1p30

BERLAND, L. K. Explaining Variation in How Classroom Communities Adapt the Practice of Scientific Argumentation. Journal of the Learning Sciences, v. 20, n. 4, p. 625-664, 2011. https://doi.org/10.1080/10508406.2011.591718

BERLAND, L. K.; HAMMER, D. Framing for scientific argumentation. Journal of Research in Science Teaching, v. 49, n. 1, p. 68-94, 2012. https://doi.org/10.1002/tea.20446

BERLAND, L. K.; MCNEILL, K. L. A learning progression for scientific argumentation: Understanding student work and designing supportive instructional contexts. Science Education, v. 94, n. 5, p. 765-793, 2010. https://doi.org/10.1002/sce.20402

BERLAND, L. K.; REISER, B. J. Classroom communities' adaptations of the practice of scientific argumentation. Science Education, v. 95, n. 2, p. 191-216, 2011. https://doi.org/10.1002/sce.20420

BERNSTEIN, B. La estructura del discurso pedagógico. Ed. 1. Madrid; La Coruña: Ediciones Morata, S. L, 1993.

BRICKER, L. A.; BELL, P. Conceptualizations of argumentation from science studies and the learning sciences and their implications for the practices of science education. Science Education, v. 92, n. 3, p. 473-498, 2008. https://doi.org/10.1002/sce.20278

CAVAGnetTO, A. R. Argument to Foster Scientific Literacy. Review of Educational Research, v. 80, n. 3, p. 336-371, 2010. https://doi.org/10.3102/0034654310376953

CHIN, C.; OSBORNE, J. Supporting Argumentation Through Students' Questions: Case Studies in Science Classrooms. Journal of the Learning Sciences, v. 19, n. 2, p. 230-284, 2010. https://doi.org/10.1080/10508400903530036

CLARK, D.; SAMPSON, V. D. Personally-Seeded Discussions to Scaffold Online Argumentation. International Journal of Science Education, v. 29, n. 3, p. 253-277, 2007. 
https://doi.org/10.1080/09500690600560944

CLARK, D.; STEGMANN, K.; WEINBERGER, A.; MENEKSE, M.; ERKENS, G. Technology-Enhanced Learning Environments to Support Students' Argumentation. In: ERDURAN, S.; JIMÉNEZ-ALEIXANDRE, M. P. (Orgs.). Argumentation in Science Education, p. 217243, 2007. Springer Netherlands. http://link.springer.com/chapter/10.1007/978-1-4020-66702_11

DRIVER, R.; NEWTON, P. Establishing the Norms of Scientific Argumentation in Classrooms. In: ESERA CONFERENCE, 1997, Roma.

DRIVER, R.; NEWTON, P.; OSBORNE, J. Establishing the norms of scientific argumentation in classrooms. Science Education, v. 84, n. 3, p. 287-312, 2000. https://doi.org/10.1002/(SICI)1098-237X(200005)84:3<287::AID-SCE1>3.0.CO;2-A

DRIVER, R.; LEACH, J.; MILLAR, R.; SCOTT, P. Young People's Images of Science. Open University Press, 1996. http://eric.ed.gov/?id=ED393679

ERDURAN, S.; SIMON, S.; OSBORNE, J. TAPping into argumentation: Developments in the application of Toulmin's Argument Pattern for studying science discourse. Science Education, v. 88, n. 6, p. 915-933, 2004. https://doi.org/10.1002/sce.20012

FERNANDES, G. W. R. Atividades de Investigação mediadas pelas TICE: estudo das concepções, interações e discussões desenvolvidas por crianças e jovens dentro de um contexto de ensino de Ciências ativo e colaborativo. 2016. Tese. (Doutorado) - Universidade de Lisboa, Portugal. https://www.repository.utl.pt/handle/10400.5/11672

GARCIA-MILA, M.; GILABERT, S.; ERDURAN, S.; FELTON, M. The Effect of Argumentative Task Goal on the Quality of Argumentative Discourse. Science Education, v. 97, n. 4, p. 497-523, 2013. https://doi.org/10.1002/sce.21057

JIMÉNEZ-ALEIXANDRE, M. P.; BUGALLO RODRÍGUEZ, A.; Duschl, R. A. "Doing the lesson" or "doing science": Argument in high school genetics. Science Education, v. 84, n. 6, p. 757-792, 2000. https://doi.org/10.1002/1098-237X(200011)84:6<757::AID-SCE5>3.0. $\mathrm{CO} ; 2-\mathrm{F}$

JIMÉNEZ-ALEIXANDRE, M. P.; PUIG, B. Argumentation, Evidence Evaluation and Critical Thinking. In. FRASER, B. J.; TOBIN, K.; McRobbie, C. J. (Orgs.). Second International Handbook of Science Education, p. 1001-1015. Springer Netherlands, 2012. http://link.springer.com/chapter/10.1007/978-1-4020-9041-7_66

LEDERMAN, N. G. Nature of Science: Past, Present, and Future. In: Handbook of Research on Science Education. Mahwah, N.J: Routledge, p. 831-879, 2007.

MORTIMER, E.; SCOTT, P. Meaning Making in Secondary Science Classrooms (1 edi- 
tion). Maidenhead; Philadelphia: Open University Press, 2003.

OSBORNE, J., ERDURAN, S.; SIMON, S. Enhancing the quality of argumentation in school science. Journal of Research in Science Teaching, v. 41, n. 10, p. 994-1020, 2004. https://doi.org/10.1002/tea.20035

SAMPSON, V.; BLANCHARD, M. R. Science teachers and scientific argumentation: Trends in views and practice. Journal of Research in Science Teaching, v. 49, n. 9, p. 1122-1148, 2012. https://doi.org/10.1002/tea.21037

SAMPSON, V.; CLARK, D. B. Assessment of the ways students generate arguments in science education: Current perspectives and recommendations for future directions. Science Education, v. 92, n. 3, p. 447-472, 2008. https://doi.org/10.1002/sce.20276

SAMPSON, V. D.; CLARK, D. B. Assessment of argument in science education: A critical review of the literature. In: INTERNATIONAL CONFERENCE OF THE LEARNING SCIENCES, 2006, Bloomington, IN. p. 655-661. Proceedings...

SASSERON, L. H. Alfabetização Científica no Ensino Fundamental: Estrutura e Indicadores deste processo em sala de aula 2008. Tese (Doutorado) - Universidade de São Paulo (USP), São Paulo.

SASSERON, L. H.; CARVALHO, A. M. O ensino de ciências para a alfabetização científica: analisando o processo por meio das argumentações em sala de aula. In: NASCIMENTO, S. S. do; PLANTIN, C. (Orgs.). Argumentação e ensino de ciências. Curitiba: Editora CRV, 2009.

SASSERON, L. H.; CARVALHO, A. M. P. de. Uma análise dos referenciais teóricos para estudo da argumentação no ensino de ciências. Ensaio Pesquisa em Educação em Ciências, v. 13, n. 3, 2011. http://www.scielo.br/pdf/epec/v13n3/1983-2117-epec-13-03-00243.pdf

SASSERON, L. H.; CARVALHO, A. M. P. de. Ações e indicadores da construção do argumento em aula de ciências. Ensaio Pesquisa em Educação em Ciências, v. 15, n. 2, p. 169189, 2013. http://www.scielo.br/pdf/epec/v15n2/1983-2117-epec-15-02-00169.pdf

SCOTT, P.; MORTIMER, E. Meaning Making in High School Science Classrooms: A Framework for Analysing Meaning Making Interactions. In: BOERSMA, K.; GOEDHART, M.; JONG, O. de; EIJKELHOF, H. (Orgs.). Research and the Quality of Science Education. Springer Netherlands, p. 395-406, 2005. http://link.springer.com/chapter/10.1007/14020-3673-6_31

SIMON, S.; JOHNSON, S.; CAVELL, S.; PARSONS, T. Promoting argumentation in primary science contexts: an analysis of students' interactions in formal and informal learning envi- 
ronments. Journal of Computer Assisted Learning, v. 28, n. 5, p. 440-453, 2012. https://doi.org/10.1111/j.1365-2729.2011.00451.x

TOULMIN, S. E. The Uses of Argument. 2 ed. Cambridge University Press, 2003.

VYGOTSKY, L. S. Mind in Society: The Development of Higher Psychological Processes. In: COLE, M.; JOHN-STEINER, V.; SCRIBNER, S.; SOUBERMAN, E. (Orgs.) New Ed edition. Cambridge: Harvard University Press, 1980.

VYGOTSKY, L. S. Thought and Language. In: KOZULIN, A. (Org.) Revised edition. Cambridge, Mass: The MIT Press, 1986.

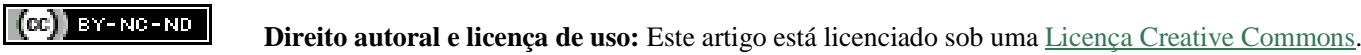

